\title{
Evaluation of WRF-SFIRE performance with field observations from the FireFlux experiment
}

\author{
A. K. Kochanski ${ }^{1}$, M. A. Jenkins ${ }^{1,2}$, J. Mandel $^{3}$, J. D. Beezley ${ }^{4}$, C. B. Clements ${ }^{5}$, and S. Krueger ${ }^{1}$ \\ ${ }^{1}$ Department of Atmospheric Science, University of Utah, Salt Lake City, UT, USA \\ ${ }^{2}$ Department of Earth and Space Science and Engineering, York University, Toronto, ON, Canada \\ ${ }^{3}$ Department of Mathematical and Statistical Sciences, University of Colorado Denver, Denver, CO, USA \\ ${ }^{4}$ Météo France and CERFACS, Toulouse, France \\ ${ }^{5}$ Department of Meteorology and Climate Science, San José State University, San José, CA, USA
}

Correspondence to: A. K. Kochanski (adam.kochanski@utah.edu)

Received: 12 November 2012 - Published in Geosci. Model Dev. Discuss.: 18 January 2013

Revised: 12 April 2013 - Accepted: 8 June 2013 - Published: 2 August 2013

\begin{abstract}
This study uses in situ measurements collected during the FireFlux field experiment to evaluate and improve the performance of the coupled atmosphere-fire model WRF-SFIRE. The simulation by WRF-SFIRE of the experimental burn shows that WRF-SFIRE is capable of providing realistic head-fire rate of spread and vertical temperature structure of the fire plume, and fire-induced surface flow and vertical velocities within the plume up to $10 \mathrm{~m}$ above ground level. The simulation captured the changes in wind speed and direction before, during, and after fire front passage, along with the arrival times of wind speed, temperature, and updraft maxima, at the two instrumented flux towers used in FireFlux. The model overestimated vertical wind speeds and underestimated horizontal wind speeds measured at tower heights above $10 \mathrm{~m}$. It is hypothesized that the limited model spatial resolution led to overestimates of the fire front depth, heat release rate, and updraft speed. However, on the whole, WRF-SFIRE simulated fire plume behavior that is consistent with FireFlux observations. The study suggests optimal experimental pre-planning, design, and execution strategies for future field campaigns that are intended to evaluate and develop further coupled atmosphere-fire models.
\end{abstract}

\section{Introduction}

Over the last two decades, significant advances have been made on the development of coupled atmosphere-fire numerical models for simulating wildland fire behavior. While numerical studies using coupled atmosphere-fire models have shed light on the dynamics of fire-atmosphere interactions (Clark et al., 1996; Morvan and Dupuy, 2001; Linn et al., 2002; Linn and Cuningham, 2005; Coen, 2005; Cunningham et al., 2005; Sun et al., 2006; Mell et al., 2007; Cunningham and Linn, 2007), none of these models have been evaluated or validated using in situ, field-scale observational data. This is due to the lack of field measurements appropriate for model testing. The objective of this study is to determine the ability of the WRF-SFIRE modeling system (Mandel et al., 2009, 2011) to predict observable phenomena accurately by comparing model output to comprehensive field measurements. Measurements made during the FireFlux field experiment (Clements et al., 2007, 2008; Clements, 2010) are used for this purpose.

No single numerical wildfire behavior prediction model available today is ideal. Existing wildfire behavior prediction models range from the mainly physical, based on fundamental understanding of the physics and chemistry involved, to the purely empirical, based on phenomenological descriptions or statistical regressions of fire behavior. As a result, these models differ greatly in terms of physical complexity, representation of atmosphere-fire coupling, extent of resolved versus parameterized processes, and computational requirements. For both research and operational use, each has its strengths and weaknesses.

WFDS (Wildland Urban-Interface Fire Dynamics Simulator; Mell et al., 2007) and FIRETEC (Linn, 1997; Linn et al., 2002) are two examples of the most advanced 
fire-scale coupled fire-atmosphere wildfire behavior models. This class of model attempts to represent localized fire-atmosphere interactions with explicit treatment of convective and radiative heat transfer processes. Computational resources are dedicated to resolving the fine-scale physics of flame, combustion, radiation, and associated convection. Unfortunately, the computational demands of these models preclude their use as operational field models for wildfire behavior forecasts. Using current computer technology, the wall clock time required to complete a wildfire simulation contained in even small-sized (e.g., $x, y, z$ dimensions less than $4 \mathrm{~km} \times 4 \mathrm{~km} \times 2 \mathrm{~m}$ ) domains is significantly greater than the simulated fire's lifespan; by the time the forecast is computed, it is already outdated. Furthermore the small domain size generates often non-physical numerical boundary effects (Mell et al., 2007). Typically run as a stand-alone model in research mode, wildfire simulations by these models lack a real-time multi-scale atmospheric boundary layer (ABL) wind and weather forecast component.

At the other end of the model spectrum are the current operational real-time wildfire behavior prediction models (Sullivan, 2009; Papadopoulos and Pavlidou, 2011). These are the simplest models that, instead of solving the governing fluid dynamical equations, rely on semi-empirical or empirical relations to provide a fire's rate of spread as a function of prescribed fuel properties, surface wind speed and humidity, and a single terrain slope. The main advantages of these models are that they are computationally very fast and can be run easily on a single laptop computer. The main disadvantage is that they are limited physically. These models consider only surface wind direction and strength, lack a real-time multi-scale wind and weather forecast component, and cannot account for coupled atmosphere/wildfire interactions. The implication is that these models perform well for cases when atmosphere-fire coupling provides for steadystate fire propagation, under environmental wind conditions stable to flow perturbations. Applications of these empirical and semi-empirical models to wildfire conditions where fireatmosphere coupling does not provide for steady-state propagation (e.g., crown or high intensity fires, or wildfires in complex terrain or changing environmental wind conditions) can lead to serious errors in fire-spread predictions (Beer, 1991; Finney, 1998).

There exists an intermediate class of wildfire behavior prediction models that may be categorized as a "quasi"-physical coupled atmosphere-fire model (Sullivan, 2009). This class of model includes the physics of the coupled fire/atmosphere but obtains heat and moisture release rates, fuel consumption, and fire-spread rate from the same prescribed formulae or semi-empirical relations that are employed by current operational fire behavior models. Based on operational fire-spread formulations driven by the coupled fire-atmosphere winds at the fire line, a simple numerical scheme is used to move the fire perimeter through the fuel and each surface model grid. Computational resources are therefore dedicated to resolving the atmospheric physics and fluid dynamics at the scale of the fire line. The highly simplified treatment of combustion, radiation, heat transfer, and surface fire spread makes these models perform significantly faster than physics-based ones, and therefore these models appear to be good candidates for future operational tools for wildfire forecasting.

Examples of this type of model are CAWFE (Coupled Atmosphere-Wildland Fire-Environment; Clark et al., 1996, 2003, 2004; Coen, 2005), fire-atmosphere coupled UU LES (University of Utah Large Eddy Simulator; e.g. Sun et al., 2009), fire-atmosphere coupled UU LES (University of Utah large eddy simulation; e.g., Sun et al., 2009), MesoNHForeFire (Filippi et al., 2009, 2013), and WRF-SFIRE (Mandel et al., 2009, 2011). Even though atmospheric and fire components differ, these models are based on the same operating principles (Sullivan, 2009). Proponents of these models argue that if the goal is a real-time operational physically based fire behavior forecast model, then this approach is feasible provided the subgrid-scale parameterizations of fire produce accurate heat release rates, and the mathematical algorithms propagating the fire at rates specified by the empirical fire-spread formulations calculate realistic spread rates under coupled fire-atmosphere wind conditions. Of these models, only WRF-SFIRE and MesoNH-ForeFire have access to a real-time multi-scale forecast of ABL flow, making them the most appropriate candidates for operational wildfire prediction.

This study attempts, therefore, to determine the ability of the WRF-SFIRE modeling system to predict accurately observable phenomena by comparing model output to comprehensive field measurements. WRF-SFIRE prediction is evaluated from the point of view of the fire front propagation (including fire-atmosphere interactions), and in situ measurements collected at the fire line during the FireFlux experiment (Clements et al., 2007) are employed for this purpose. FireFlux's fire line, wind, and temperature measurements are used to evaluate and improve WRF-SFIRE fire line's predicted ROS (rate of spread), temperatures, and winds. The uniqueness of FireFlux compared to the open grassland fire experiments conducted in Australia (Cheney et al., 1993; Cheney and Gould, 1995) is that it provides details of the plume and atmosphere structure during the fire front passage (FFP), rather than focus on fire line depth and spread. When comparisons between observations and WRF-SFIRE predictions indicated good agreement, the simulation was used to display the flow features observed during FireFlux in terms of WRFSFIRE predicted fire spread, plume properties, and behavior.

For an analysis of the effect of model resolution on FireFlux simulation in SFIRE, see Kochanski et al. (2011). A study of the FireFlux experiment with MesoNH-ForeFire is now also available by Filippi et al. (2013).

The paper is organized as follows. Section 2 describes the field experiment used for the WRF-SFIRE model evaluation. The model description and its setup are described in Sects. 3 and 4. Results on fire spread, and thermal and 
dynamical plume properties, and the structure of the fireinduced flow are presented in Sect. 5 and compared to FireFlux observations. In Sect. 6, adjustments made to WRFSFIRE to obtain the agreement with FireFlux observations are discussed, and suggestions are made for the design of future field campaigns to deliver the observations necessary for evaluation or validation of existing coupled atmosphere-fire prediction models. Concluding remarks are given in Sect. 7.

\section{Overview of the FireFlux experiment}

A major difficulty in developing realistic wildfire behavior prediction models is the lack of observational data in the immediate environment of wildland fires that can be used for validating these models (Clements et al., 2007). One the first experiments addressing this issue is the FireFlux experiment, which took place on 23 February 2006 at the Houston Coastal Center, a 1000 acre research facility of the University of Houston. The FireFlux experiment is the most intensively instrumented grass fire to date. The experiment was designed to study fire-atmosphere interactions during a fastmoving head fire in grass fuels by measuring the wind, turbulence, and thermodynamic fields of the near-surface environment and of the plume. An overview of the experimental design, and results of the turbulence and thermodynamic measurements are found in Clements et al. $(2007,2008)$ and Clements (2010), respectively.

Figure 1 shows the experimental layout with instrument locations. The key platforms included a multi-level $43 \mathrm{~m} \mathrm{mi-}$ crometeorological flux tower located in the middle of the fuel bed and a similarly instrumented, but shorter, $10 \mathrm{~m}$ tower located $300 \mathrm{~m}$ downwind from the $43 \mathrm{~m}$ main tower. These two towers are hereafter referred to as MT (for main tower) and ST (for short tower). In addition to MT and ST, a tethered balloon system was deployed on the downwind edge of the burn block to measure temperature, humidity, and wind speed and direction at five altitudes up to $150 \mathrm{~m}$ above ground level (a.g.1.). Two sodars were also used: one was a mediumrange system located on the northwest corner of the fuel bed, and the other a mini-sodar located at the southeastern corner of the burn block. Additionally, a radiosonde was released at the edge of the burn block, providing a full in situ vertical sounding of temperature, humidity, wind speed and wind direction. Video and time-lapse photography were used to record fire behavior and the spread rate of the fire front. The heights of the sensors used in this study are summarized in Table 1. For the full description of the FireFlux instrumentation, the reader is referred to Clements et al. (2007) (their Table 1).

\section{Model description}

WRF-SFIRE (Mandel et al., 2009, 2011) combines the Weather Research and Forecasting Model (WRF) with a

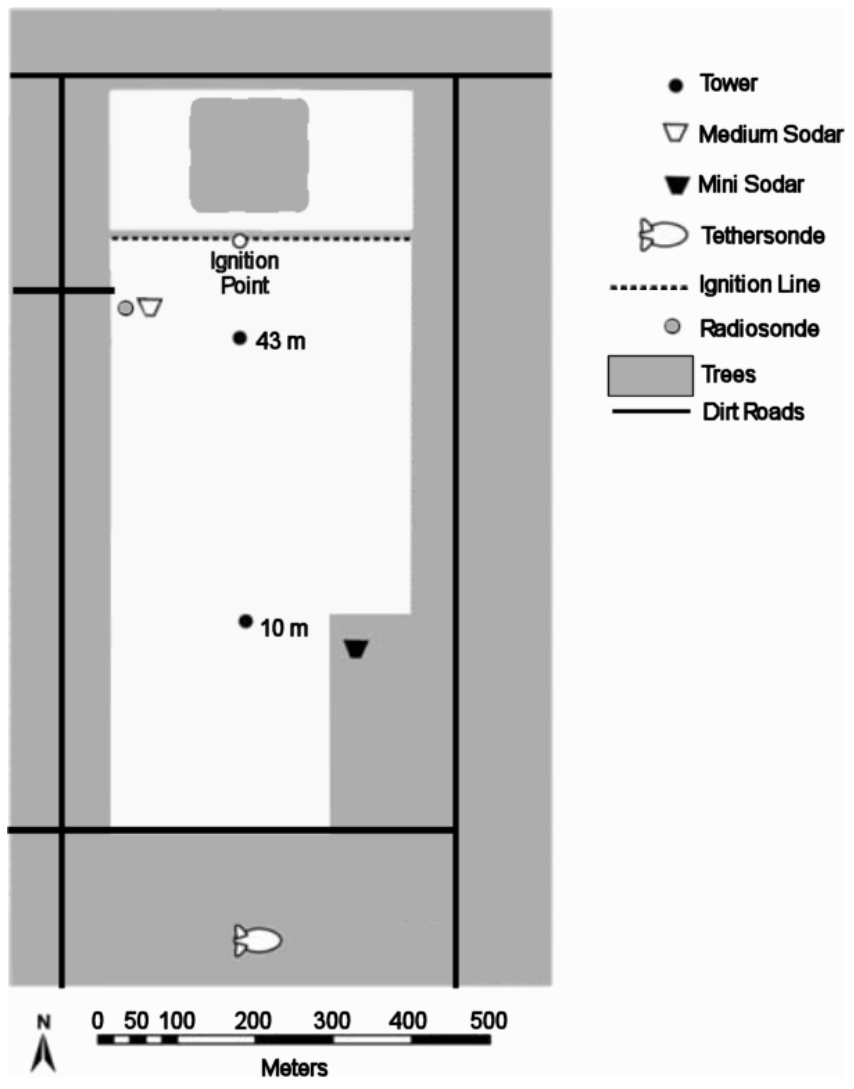

Fig. 1. Instrument locations and the layout of the FireFlux experiment. White area indicates grass.

semi-empirical or empirical fire-spread model. The fire model and the fire-atmosphere coupling are an outgrowth of CAWFE code (Clark et al., 2004). The fire model runs on a refined mesh at surface level. In each model time step, the near-surface wind from WRF is interpolated vertically to a logarithmic profile and horizontally to the fire mesh to obtain height-specific wind that is input into the user-chosen fire spread-rate formula. In this study the Rothermel fire spread-rate formula (Rothermel, 1972) was used to determine, based on the fuel properties and WRF-SFIRE winds, the instantaneous fire-spread rate at every refined mesh point. Fire propagation is implemented on the fire mesh by the level-set method (Osher and Fedkiw, 2003) and applying Rothermel's fire-spread formula in the direction normal to the fire line. After ignition, the amount of fuel remaining is assumed to decrease exponentially with time, with the time constant dependent on fuel properties. The latent and sensible heat fluxes from the fuel burned during the time step are computed based on the fuel properties and the local rate of spread, and then averaged over the cell of the atmosphere model and inserted into the lowest levels of the atmospheric model, assuming exponential decay of the heat flux with height. Fuels are given as 1 of 13 categories (Anderson, 1982), and associated with each category are prescribed fuel 
Table 1. Summary of instrumentation used for model validation.

\begin{tabular}{llllc}
\hline Platform & Type & Variable & $\begin{array}{c}\text { Measurement } \\
\text { heights } \\
\text { (m a.g.1.) }\end{array}$ & $\begin{array}{c}\text { Sampling } \\
\text { frequency }\end{array}$ \\
\hline Main & 3-D sonic anemometers (R.M. Young 81000) & $u, v, w$ wind speed components & $2.1,10,28.5,43$ & $20 \mathrm{~Hz}$ \\
Tower & Type-K thermocouple & temperature & 2.1 & $1 \mathrm{~Hz}$ \\
(MT) & Type-T thermocouples & temperature & $4.5,10,28,43$ & $1 \mathrm{~Hz}$ \\
\hline Short & 3-D sonic anemometers (R.M. Young 81000) & $u, v, w$ wind speed components & $2.3,10$ & $20 \mathrm{~Hz}$ \\
Tower (ST) & Type-T thermocouples & temperature & $2,5,10$ & $1 \mathrm{~Hz}$ \\
\hline
\end{tabular}

properties such fuel mass, depth, density, surface-to-volume ratio, moisture of extinction, and mineral content. The model supports point, instantaneous line, and "walking" ignitions. The SFIRE model is embedded into the WRF modeling framework, enabling easy setup of idealized cases or real cases requiring realistic meteorological forcing and a detailed description of the fuel types and topography. The nesting capabilities of WRF (not used in this study) allow for running the model in multi-scale configurations, where the outer domain, set at relatively low resolution, resolves the large-scale synoptic flow, while the gradually increasing resolution of the inner domains allows for realistic representation of smaller and smaller scales, required for realistic rendering of the fire convection and behavior. The SFIRE model is available from openwfm.org. A limited version from 2010 is available in WRF release as WRF-Fire, as documented in OpenWFM (2012) and discussed in Coen et al. (2013).

\section{Model setup}

The WRF modeling framework is used for routine numerical weather prediction in the United States, and its incorporation in WRF-SFIRE allows for detailed descriptions of the land use and fuel types (Beezley et al., 2010; Beezley, 2011). In this study, these capabilities were extended to the use of standard land surface models, custom topography, and land use and fuel categories (defined in external files), without the need of the WRF preprocessing system. The aerial picture of the experimental site, model domain boundary, land use, fuel map, and ignition line are presented in Fig. 2.

The fuel map used in the WRF-SFIRE FireFlux simulation was initialized with the map of land use derived from an aerial Google Earth picture and simplified to two USGS land use types: mixed forest and grassland. The grass fuel was designated as tall grass fuel, category 3, and the surrounding area as noncombustible fuel, category 4 (Anderson, 1982). More details about the fuel characteristics are given in Table 2. Model surface properties defaulted to either one of these two fuel categories. The grass roughness length was determined to be $0.02 \mathrm{~m}$ according to the pre-fire wind profile measurements from the FireFlux experiment. a)

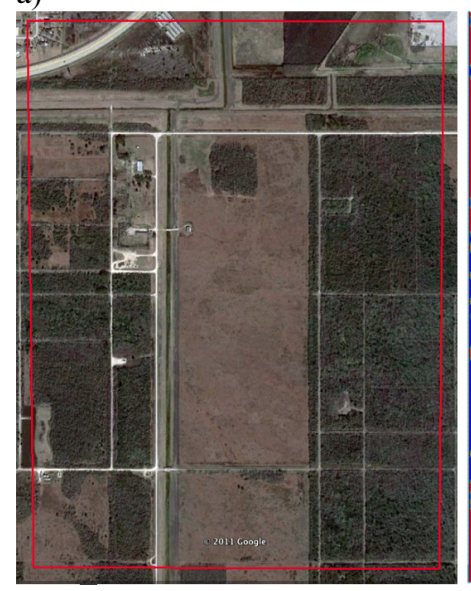

b)

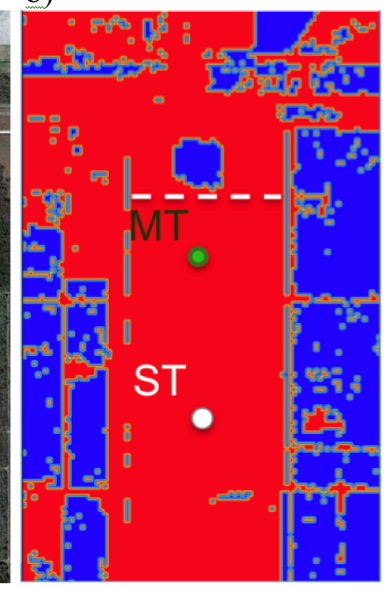

Fig. 2. (a) Aerial picture of the FireFlux area with the domain boundary marked in red; (b) "land use" field from WRF input (red signifies grassland; blue signifies mixed forest) with locations of main tower (MT; green dot), short tower (ST; white dot), and ignition line (white dashed line).

The $[x, y, z]$ dimensions of the model domain are $[1000 \mathrm{~m}$, $1600 \mathrm{~m}, 1200 \mathrm{~m}]$. The WRF atmospheric computations were performed on a regular horizontal grid of $10 \mathrm{~m}$ spacing and of non-uniform vertical-grid spacing, stretched using a hyperbolic function, varying from $2 \mathrm{~m}$ at the surface to almost $34 \mathrm{~m}$ at model top. The fire model mesh was 20 times finer than the atmospheric $x, y$ mesh, which translates into a $0.5 \mathrm{~m}$ horizontal grid spacing. The computational details are presented in Table 2.

Thermocouple measurements at $0.13 \mathrm{~m}$ a.g.l. reported a uniform fire domain temperature of $19.22^{\circ} \mathrm{C}$ before ignition, and this value was used as the model's initial surface temperature. Initial wind, temperature, and moisture fields were reconstructed using vertical profiles taken from the MT measurements up to $43 \mathrm{ma.g.l}$., the tethersonde measurements for 43-130 ma.g.l., and the morning sounding measurements for $130-1200 \mathrm{~m}$ a.g.l. The initial model profiles for wind speed and direction, and potential temperature are displayed in Fig. 3. The atmosphere was slightly unstable for the first $50 \mathrm{ma}$ a.g.l. due to solar heating of 
Table 2. Details of the numerical setup used for the FireFlux simulation.

\begin{tabular}{ll}
\hline Simulation type & LES (large eddy simulation) \\
\hline Horizontal domain size & $1000 \mathrm{~m} \times 1600 \mathrm{~m}$ \\
Atmospheric mesh & $160 \times 100 \times 80$ grid points \\
Horizontal resolution (atmospheric mesh) & $10 \mathrm{~m}$ \\
Model top & $1200 \mathrm{~m}$ \\
Vertical resolution (atmospheric mesh) & From $2 \mathrm{~m}$ at the surface to $33.75 \mathrm{~m}$ at the model top \\
Fire mesh & $3200 \times 2000$ grid points \\
Horizontal resolution (fire mesh) & $0.5 \mathrm{~m}$ \\
Simulation length & $20 \mathrm{~min}$ \\
Time step & $0.02 \mathrm{~s}$ \\
Subgrid-scale closure & $1.5 \mathrm{TKE}$ \\
Lateral boundary conditions & Open \\
Surface layer physics & Monin-Obukhov similarity theory (sf_sfclay_phys = 1) \\
Land surface model & SLAB 5-layer MM5 model (sf_surface_physics=1) \\
Ignition time & $12: 43: 30$ CST \\
Length of the western ignition line & $170 \mathrm{~m}$ \\
Duration of the western ignition & $153 \mathrm{~s}$ \\
Length of the eastern ignition line & $215 \mathrm{~m}$ \\
Duration the eastern ignition line & $163 \mathrm{~s}$ \\
Thickness of the ignition line & $1 \mathrm{~m}$ \\
Heat extinction depth & $6 \mathrm{~m}$ \\
Default (no wind, no slope) rate of spread & $0.1 \mathrm{~m} \mathrm{~s}-1$ \\
Fuel depth & $1.35 \mathrm{~m}$ \\
Ground fuel moisture & $18 \%$ \\
Fuel load & $1.08 \mathrm{~kg} \mathrm{~m}$ \\
Fuel type of the burnt area & $3($ tall grass) \\
\hline
\end{tabular}

the surface, and neutral above and up to approximately $400 \mathrm{~m}$ a.g.l. The wind was northerly at $3 \mathrm{~m} \mathrm{~s}^{-1}$ for the first $2 \mathrm{ma.g.1.}$, and increasing in magnitude with height to approximately $7 \mathrm{~m} \mathrm{~s}^{-1}$ at $50 \mathrm{~m}$ a.g.l. and becoming more northnorthwesterly. At higher levels, up to $400 \mathrm{~m}$, wind speed was fairly uniform, averaging about $8 \mathrm{~ms}^{-1}$. There was a marked deviation in wind speed and direction at approximately $50 \mathrm{~m}$ a.g.l. The reason for this is unknown, but is presumed to be an artifact of combining tower and tethersonde data. However, this deviation was not removed from the data set.

WRF-SFIRE's “walking ignition" option was used to emulate the start of the fire. Fire line ignition started at the approximate center of the burn area (see Fig. 1) and progressed laterally at the speed estimated by GPS data collected during the actual ignition procedure. Since the GPS unit recorded only one ignition branch, the timing of the other branch was based on data collected during a walk along the ignition line after the actual ignition procedure. The overall length of the ignition line was $385 \mathrm{~m}$. The ignition procedure took about $2.5 \mathrm{~min}$, while the whole burn took about $17 \mathrm{~min}$. More details on the ignition procedure are given in Table 2.

In previous versions of WRF-SFIRE, a point ignition was modeled by setting a fixed circle on fire at once, with the circle size at least the size of a horizontal fire cell, while a walking ignition was modeled as a succession of circles.
In this study, such a walking-ignition scheme produced an ignition line at least $0.5 \mathrm{~m}$ wide, while FireFlux's dip torch ignition line was likely thinner; the $0.5 \mathrm{~m}$ wide ignition strip caused the initial fire propagation to be too fast. Therefore, to prevent this, the WRF-SFIRE ignition model was revised to apply a slower initial subgrid ROS during the time period from ignition until the fire is large enough to be visible on the fire mesh, after which time the propagation mechanism based on the Rothermel formulation takes over. See Sect. 3.6 in Mandel et al. (2011) for the details of the ignition implementation in the framework of the level-set method.

In addition, to achieve a realistic fire propagation rate between ignition of the initial fire line and FFP at the MT, the Rothermel default no-wind fire line rate of spread (ROS) was increased from $0.02 \mathrm{~m} \mathrm{~s}^{-1}$ to $0.1 \mathrm{~m} \mathrm{~s}^{-1}$ (Table 2). This ROS is applied when there is no wind component perpendicular to the leading edge of the subgrid-scale combustion zone. Comparison with flank ROS simulated by FIRETEC (Cunningham and Linn, 2007) for grass fires suggests that $0.02 \mathrm{~m} \mathrm{~s}^{-1}$ is an order of magnitude too small. The five-fold increase in no-wind ROS also resulted in more realistic spread along the fire's flanks and back (upwind) side.

One of the parameters that is hard to measure precisely, but is important for the rate of spread computation, is the fuel height. Clements et al. (2007) estimated it to be $1.5 \mathrm{~m}$, 

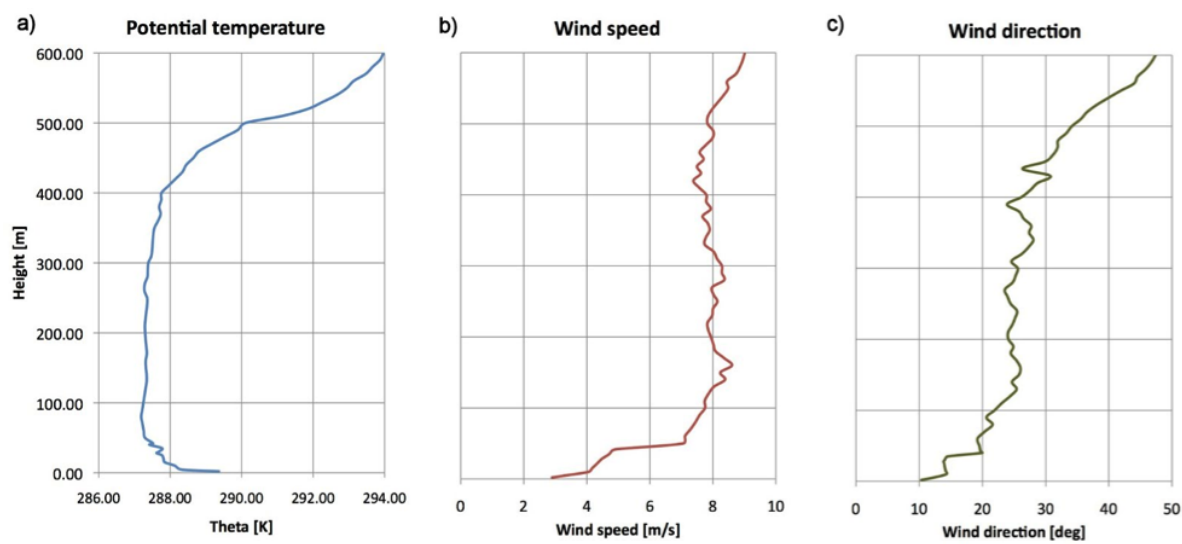

Fig. 3. Initial atmospheric profiles used for model initialization: (a) potential temperature, (b) wind speed, and (c) wind direction.

but precise measurements were not taken. For the sake of this study, we set it to $1.35 \mathrm{~m}$.

Another fire model feature that was set to provide good agreement with observations was the e-folding extinction depth used to parameterize the transport of sensible, latent, and radiant heat from the fire's combustion zone into the near-surface layers of WRF. In WRF-SFIRE, the total heat liberated into the atmosphere by the fire is released vertically into the model atmosphere using the e-folding extinction depth. Sun et al. (2006, 2009), following Clark et al. (1996b), also used this simple extinction depth approach to treat the fire-atmosphere heat exchange. Sun et al. (2006) found that plume-averaged properties were sensitive to the choice of extinction depth; too large an extinction depth underestimated important near-surface properties just above the combustion zone, such as temperature excess and vertical plume velocity; too small an extinction depth produced agreement between observed and model-predicted plume-averaged temperatures, but less agreement between observed and modelpredicted plume-averaged vertical velocities just above the surface. There exists therefore no unique value for this parameter. In this study the flame length estimate of $5.1 \mathrm{~m}$ by Clements et al. (2007) was used to set the extinction depth to $6 \mathrm{~m}$.

Unfortunately, the infrared video camera used to record the fire experienced technical problems, and continuous infrared imagery of the location and spread rate of the fire head is not available for analysis. Wind and air temperature measurements are used instead to represent head fire spread, plume properties, and behavior. Note that the FireFlux temperatures used in this study were measured by a type-T thermocouple sampled at $1 \mathrm{~Hz}$ (Clements et al., 2007; their Table 1). FireFlux temperatures were also measured at $2.1 \mathrm{~m}$ a.g.l. at the MT and $2.3 \mathrm{~m}$ a.g.l. at the ST with a type-K fine-wire $20 \mathrm{~Hz}$ thermocouple. Because the fine-wire thermocouples failed at times, and measurements below $2.5 \mathrm{~m}$ a.g.l. were possibly affected by precautions taken to shield these thermocouples (i.e., grass was mowed around the towers) from damage by the fire, these data are not used in the evaluation of WRF-SFIRE output.

Horizontal atmospheric grid resolution limits the frequency of the fluctuations in temperatures or flow that the model can resolve. For the atmospheric horizontal grid size of $10 \mathrm{~m}$, the shortest disturbance or fluctuation that the model resolves is assumed to have an approximate length of $40 \mathrm{~m}$. If this perturbation travels at $8 \mathrm{~m} \mathrm{~s}^{-1}$, roughly the peak wind speed observed during FireFlux, the effective frequency of disturbance resolved by the model is $1 /(8 / 40)$ or $0.2 \mathrm{~Hz}$. Therefore, the WRF-SFIRE output frequency was $0.2 \mathrm{~Hz}$ (i.e., results were saved every $5 \mathrm{~s}$ ), and a $5 \mathrm{~s}$ moving average was applied to the FireFlux measurements for direct comparison to model results.

\section{Results}

\subsection{Fire spread}

Fire-spread rates are determined by the time series of $4.5 \mathrm{~m}$ a.g.l. at the MT and $5 \mathrm{~m}$ a.g.l. at the ST simulated and observed air temperatures shown in Fig. 4 (gray lines show $1 \mathrm{~Hz}$ thermocouple data, and black lines show $5 \mathrm{~s}$ averaged $1 \mathrm{~Hz}$ thermocouple data). Model results are interpolated vertically between second $(4.49 \mathrm{~m})$ and third $(7.7 \mathrm{~m})$ model levels. The timing of FireFlux's FFP through the MT is indicated by rapidly rising and falling air temperatures in the time series. This timing is well captured by WRF-SFIRE. The simulated MT air temperature reached the peak value at $225 \mathrm{~s}$ after the ignition, while observations indicate a peak temperature just $6 \mathrm{~s}$ earlier. Timing of the FFP through the ST is also well captured by the model. There is only a $5 \mathrm{~s}$ delay with respect to the observations, and the simulated ROS between the two towers is $1.61 \mathrm{~m} \mathrm{~s}^{-1}$, exactly the observed ROS. 


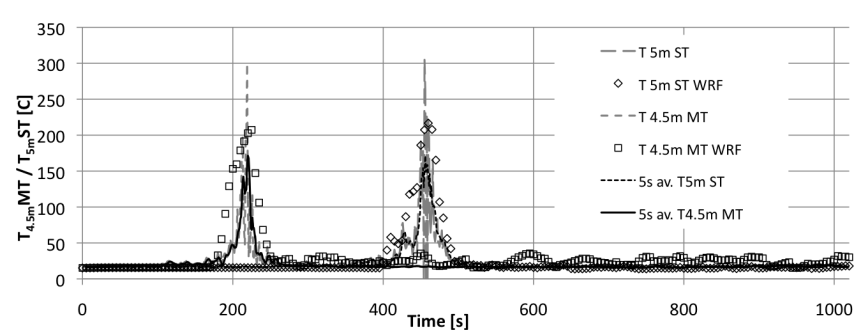

Fig. 4. Time series of the $4.5 \mathrm{~m}$ a.g.l. air temperature at the location of the main tower (MT) and $5 \mathrm{~m}$ a.g.l. air temperature at the short tower (ST). Gray lines show $1 \mathrm{~Hz}$ measurements, black lines $5 \mathrm{~s}$ averaged values, and symbols (diamond and square) model data.

\subsection{Thermal plume structure}

In terms of magnitude, the agreement between observed and simulated temperatures is relatively good. Figure 4 indicates that the WRF-SFIRE's peak air temperature at the MT is $35 \mathrm{~K}$ warmer than the $5 \mathrm{~s}$ averaged measurements and $88 \mathrm{~K}$ cooler than the maximum temperature from the $1 \mathrm{~Hz}$ thermocouple data. The data from the type-T thermocouple (sampling frequency $1 \mathrm{~Hz}$ ) at $4.5 \mathrm{~m}$ a.g.l. were used. However, we believe, based on a comparison between temperatures taken from the type- $\mathrm{T}$ and type- $\mathrm{K}$ fine-wire thermocouples at the sonic locations ( $2.1 \mathrm{~m}$ on MT and $2.3 \mathrm{~m}$ on ST), that the type- $\mathrm{T}$ thermocouple, after $5 \mathrm{~s}$ averaging, tended to underestimate temperatures by sometimes as much as $90 \mathrm{~K}$ and $32 \mathrm{~K}$. This suggests that simulated air temperatures are within only $3 \mathrm{~K}$ of temperatures measured with the faster responding fine-wire thermocouple. Figure 4 shows that ST thermocouple temperatures are slightly higher than those at MT. Temperature maxima are $304^{\circ} \mathrm{C}$ at the ST and $295^{\circ} \mathrm{C}$ at the MT. The simulated peak temperature at the ST is also $9 \mathrm{~K}$ higher than the simulated peak temperature at the MT. These differences are eliminated by $5 \mathrm{~s}$ averaging. The filtered peak air temperature is $172{ }^{\circ} \mathrm{C}$ at the MT and $171^{\circ} \mathrm{C}$ at the ST. The model again underestimated the $4.5 \mathrm{~m}$ a.g.l. air temperature at the ST by $88 \mathrm{~K}$, almost exactly the bias between model and $1 \mathrm{~Hz}$ temperature data at MT. Compared with the filtered data, the model overestimated the ST air temperature by $45 \mathrm{~K}$.

Figure 5 is the same as Fig. 4 except for time series plots at the MT at $2 \mathrm{~m}, 10 \mathrm{~m}, 28 \mathrm{~m}$ and $43 \mathrm{~m}$ a.g.l., and demonstrates how well WRF-SFIRE plume's vertical temperature profile matches the tower thermocouple temperature measurements. Tower temperatures before and after fire passage remain steady and deviate very little from the background temperature. This behavior is well predicted by WRF-SFIRE. Figure 5a and $\mathrm{b}$ show that temperatures in the WRF-SFIRE plume begin to rise above and then fall to ambient (no fire) values at virtually the same times as FireFlux plume values: fire-plume arrival and passage are practically identical for both measured and simulated plumes. However, changes in observed temperature with fire passage do differ
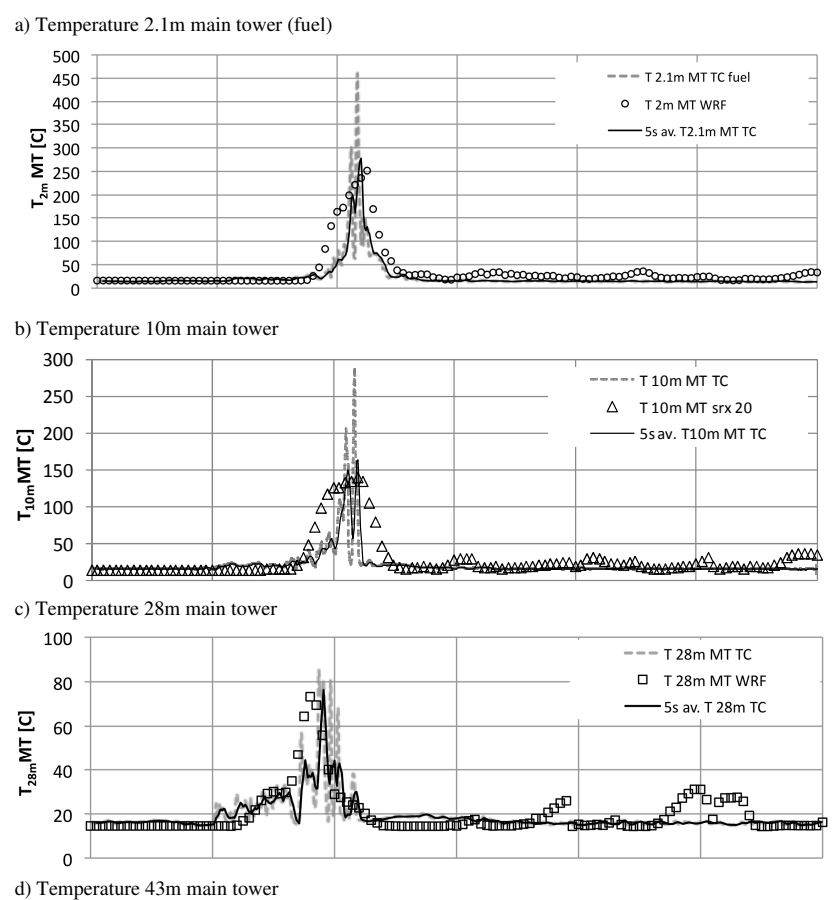

d) Temperature $43 \mathrm{~m}$ main tower

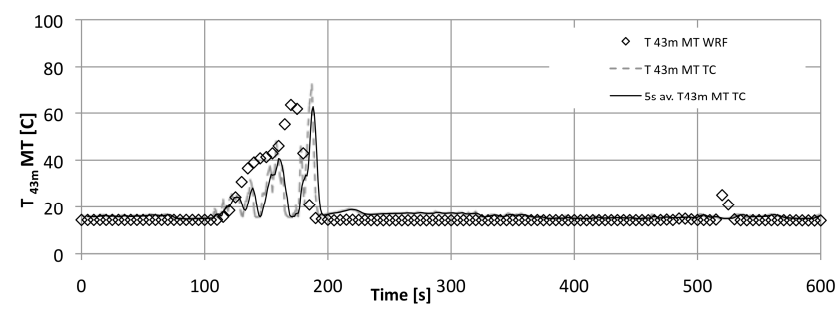

Fig. 5. Time series of the thermocouple air temperatures at the location of the MT at (a) $2.1 \mathrm{~m}$, (b) $10 \mathrm{~m}$, (c) $28 \mathrm{~m}$, and (d) $43 \mathrm{~m}$ a.g.l. Gray lines show $1 \mathrm{~Hz}$ measurements, black lines $5 \mathrm{~s}$ averaged values, symbols (open circles, triangles, squares, and diamonds) model data.

from the model results. FireFlux temperatures rise slightly just ahead of a rapid increase to peak temperature values, while model temperatures do not show a strong tendency towards "preheating" and generally begin a more immediate but less abrupt rise. While FireFlux temperatures peak, decline abruptly, and then decay away to almost ambient values as the fire passes, the smooth fall in WRF-SFIRE temperatures after the peak generally matches the smooth rise in temperatures before the peak. At higher elevations (Fig. 5c and d), the WRF-SFIRE plume temperatures rise on average at almost the same rate, but fall sooner than the FireFlux temperatures. This temporal shift may be attributed to either a slight underestimation in the simulated horizontal plume extent at higher elevations or that the fine-scale fire plume structure is unresolved in the WRF-SFIRE simulation. The generally slow rise and fall in simulated temperatures may be the consequence of either the coarse model output time interval $(5 \mathrm{~s})$, or the relatively coarse atmospheric grid volume over 
which model variables are averaged. These model oversimplifications may also be responsible for the unrealistic lack of spatial and temporal temperature (and wind) fluctuations in the WRF-SFIRE plume, especially at levels $>10 \mathrm{~m}$ a.g.l. Differences between model and FireFlux thermocouple temperatures are to a great degree eliminated by $5 \mathrm{~s}$ averaging. When the WRF-SFIRE temperature time series in Figs. 4, 5a and $\mathrm{b}$ are compared to the $5 \mathrm{~s}$ moving mean of the FireFlux temperatures, a greater level of agreement is seen. To a moderate degree, WRF-SFIRE overpredicts fire plume temperatures (by $35 \mathrm{~K}$ ) at $4.5 \mathrm{~m}$ a.g.l. but agrees within $25 \mathrm{~K}$ at all other levels.

Figure $5 \mathrm{c}$ and $\mathrm{d}$ show the upper levels of the warm, downwind-tilted FireFlux plume arriving, respectively, at the main tower just at and after $100 \mathrm{~s}$ into the experiment. Plume arrival occurs slightly sooner at $28 \mathrm{~m}$ a.g.l. compared to $43 \mathrm{~m}$ a.g.l., and plume passage occurs later at $28 \mathrm{~m}$ a.g.l. compared to $43 \mathrm{~m}$ a.g.l. Although the WRF-SFIRE temperature time series in Fig. 5c and d do not show plume arrival at lower levels first, the temporal differences in fire-plume arrival and passage between FireFlux and WRF-SFIRE at these al these levels (AGLs) are slight. Measured plume temperatures as well as the $5 \mathrm{~s}$ moving means during fire passage show significant fluctuations in magnitude at both $28 \mathrm{~m}$ and $43 \mathrm{~m}$ a.g.l. Fluctuations of this magnitude are not unexpected in the upper portion of an entraining, turbulent fire plume. The results indicate that even though the WRF-SFIRE did not capture these high-frequency fluctuations, it predicted the FireFlux peak temperatures at $28 \mathrm{~m}$ and $43 \mathrm{~m}$ a.g.l. very accurately (with $9 \mathrm{~K}$ and $1 \mathrm{~K}$ bias, respectively). Time of plume arrival is well predicted by WRF-SFIRE at the $43 \mathrm{~m}$ level and underpredicted by approximately $20 \mathrm{~s}$ at the $28 \mathrm{~m}$ level. The abrupt falloff in measured plume temperatures as the upwind edge of the plume passes the tower is well represented in the WRF-SFIRE time series. Temperature measurements at $43 \mathrm{~m}$ show that air temperatures remain slightly elevated above ambient values even after the plume has passed, while temperatures measured just $1 \mathrm{~m}$ below (not shown) and simulated by WRF-SFIRE drop immediately to pre-fire ambient values. However, local variation of plume properties in the upper levels of a highly turbulent convective plume is not unrealistic, which suggests that this level of agreement between predicted results and measurements is remarkable. Clements (2010) reports that the greatest temperature difference and variability compared to ambient air temperatures occurred at $10 \mathrm{~m}$ a.g.l., where entrainment of ambient air is possibly the greatest.

Figure 6 is the same as Fig. 5 except for time series plots at the ST at $2 \mathrm{~m}$ and $10 \mathrm{~m}$ a.g.l. Fire-plume arrival and passage are practically identical for both measured and simulated plumes. However, WRF-SFIRE overestimates plume temperatures at these two levels. Simulated fire-plume temperatures are within $25 \mathrm{~K}$ of the $1 \mathrm{~Hz}$ observations, but greater by $82 \mathrm{~K}$ at $2 \mathrm{~m}$ a.g.l. and $45 \mathrm{~K}$ at $10 \mathrm{ma}$ a.g.l. than peak $5 \mathrm{~s}$ moving means, and they remain elevated for a significantly

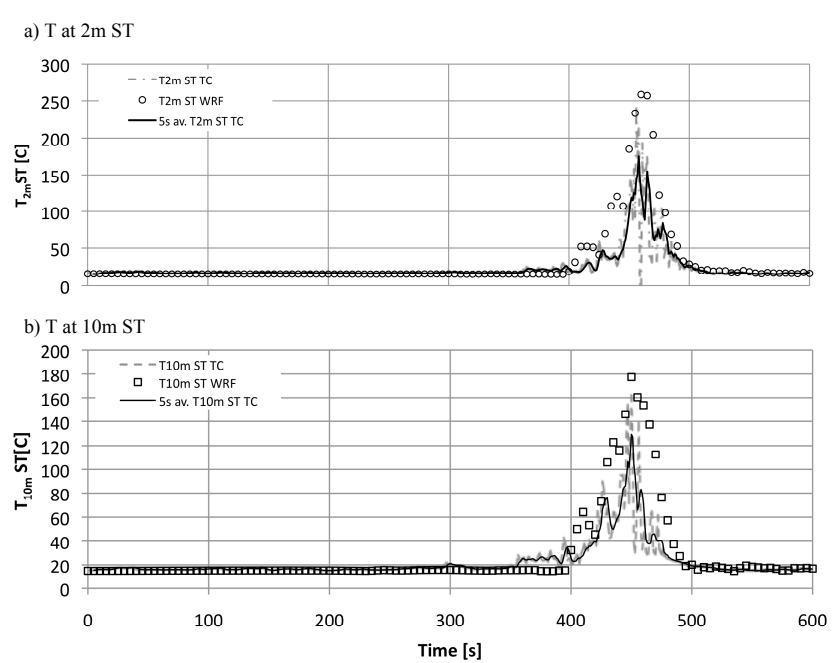

Fig. 6. Time series of the thermocouple air temperatures at the location of the short tower (ST) at (a) $2 \mathrm{~m}$ and (b) $10 \mathrm{~m}$. Gray dashed lines show $1 \mathrm{~Hz}$ measurements, black solid lines $5 \mathrm{~s}$ averaged values, and symbols (open circles and squares) model data.

longer time than measured ones. Due to the lack of infrared video camera recordings, it is difficult to report the actual fire front depth. However, differences in the time periods between simulated and observed fire plume temperature values suggest that the model is overestimating the thickness of the fire front. Using a $100 \mathrm{~kW} \mathrm{~m}^{-2}$ heat release rate threshold, the simulated fire front thickness at the ST is estimated as $45 \mathrm{~m}$, which appears to be too large. Note that, at the MT, the fire front thickness is estimated to be half as large, only $27.5 \mathrm{~m}$ thick. This $45 \mathrm{~m}$ front thickness is likely responsible for an unreasonably higher fire heat release and consequently unrealistically higher model fire-plume temperatures at the ST.

Figure 7 shows plots of contoured WRF-simulated (upper plot) and thermocouple-measured (middle and lower plots) temperatures at the MT as a function of time. Figure $7 \mathrm{c}$ and b show that heating by the FireFlux fire front and passage is rapid and limited to a small volume (below $15 \mathrm{~m}$ a.g.1.) around the combustion zone as the fire front quickly propagates downstream. Owing to entrainment and turbulent convection in the plume, FireFlux temperatures display a large degree of variance (Clements et al., 2008; Clements, 2010). The averaged measured temperature maximum starts around $210 \mathrm{~s}$ and lasts until $220 \mathrm{~s}$ after ignition (Fig. 7b). That implies that the fire front thickness computed based on the average rate of spread between the towers was probably no greater than $6.2 \mathrm{~m}\left(10 \mathrm{~s} / 1.61 \mathrm{~m} \mathrm{~s}^{-1}\right)$. The simulated temperature maximum starts at a similar time, but lasts significantly longer (until $235 \mathrm{~s}$ ), indicating that the thickness of the simulated fire front was at least three times wider than the observed one. As discussed in Sect. 4, the horizontal resolution of the atmospheric model directly controls the minimum 
a)

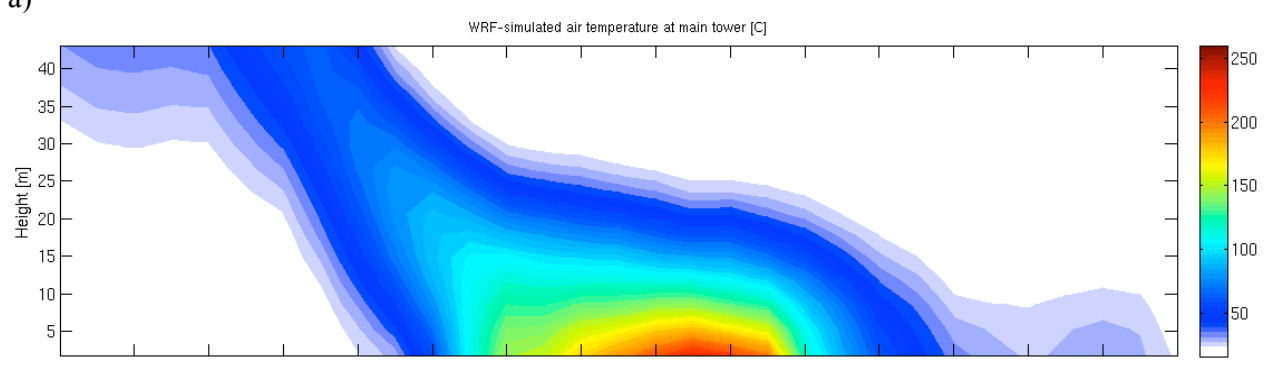

b)

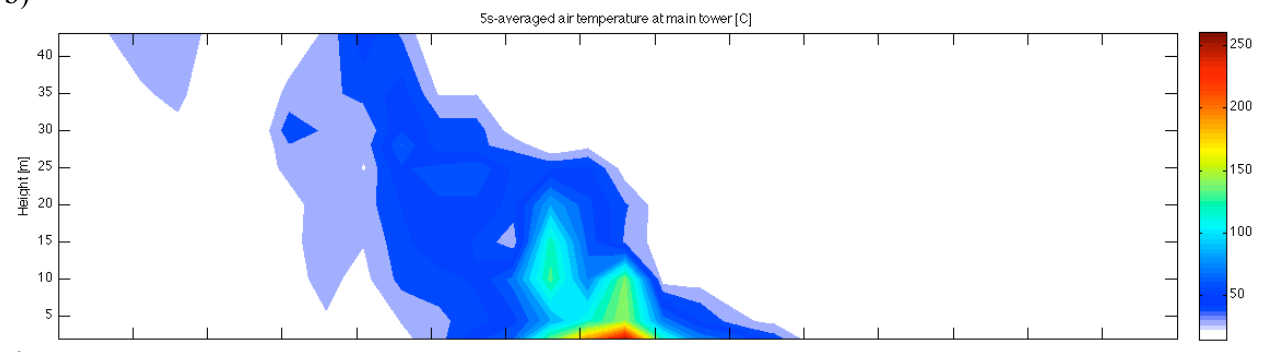

c)

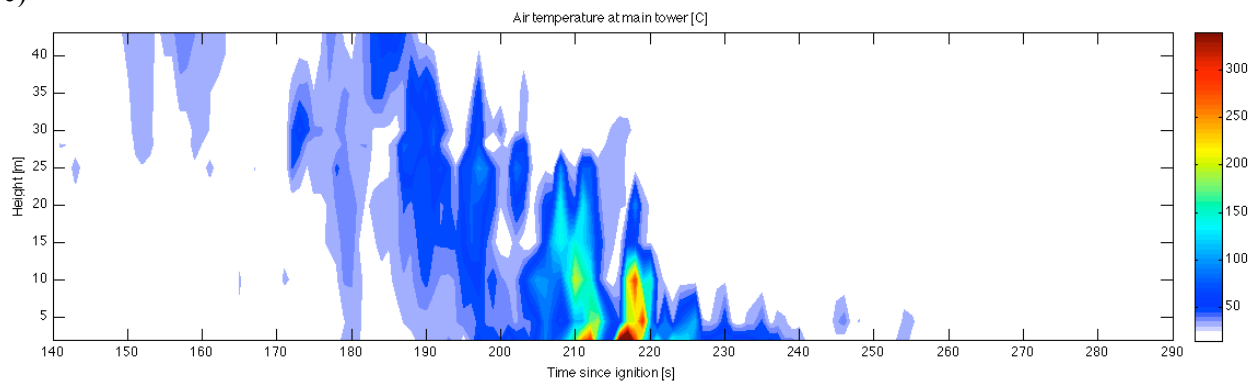

Fig. 7. Air temperatures at the MT as a function of time: (a) WRF-simulated, (b) thermocouple $5 \mathrm{~s}$ averaged, and (c) thermocouple raw (1 s).

width of the temperature perturbation that can be resolved. The averaging of heat released by the fire over the whole atmospheric grid-volume affects the appearance of the fire signal on the atmospheric mesh. Regardless of how narrow the fire front on the fine fire mesh is, as the fire crosses two adjacent atmospheric cells, the heat released is averaged over the two cells. As a consequence the minimum width of the fire-related thermal signal seen on the atmospheric grid is two atmospheric grid spaces, which in this study is $20 \mathrm{~m}$, far greater than the estimated $6.2 \mathrm{~m}$ fire-front thickness. The fuel burn rate used in WRF-SFIRE is the same for all fuel types, which may result in a too-long fuel residence time for quickly burning fuels like grass. This may also result in the overestimation in the width of the fire zone as evident in Fig. 7a.

Nonetheless, Fig. 7 shows that WRF-SFIRE successfully captured the plume's downstream tilt, the arrival between 180 and $200 \mathrm{~s}$ of fire-warmed surface air, and the passage of the fire-warmed surface air at approximately $260 \mathrm{~s}$, with the low-level near-surface warmest volume of air arriving approximately $10 \mathrm{~s}$ later at the MT than observed. Contoured WRF results also show that the $15 \mathrm{~m}$ vertical extent of the warmest (greater than $100^{\circ} \mathrm{C}$ ) plume temperatures matches the observations presented in Fig. 7b.

\subsection{Dynamical plume structure}

\subsubsection{Fire-induced horizontal winds}

WRF-SFIRE computes the ROS based on coupled fireatmosphere winds at the fire line. It is crucial, therefore, for realistic prediction of wildfire behavior that WRF-SFIRE captures accurately the fire-atmosphere interaction and evolution of the surface flow at the fire line. To evaluate for this, model results are compared to FireFlux wind measurements. Heat and temperature extremes did cause some minor damage and instrument failure during FireFlux. The sonic anemometer at the ST broke during the FFP. Therefore in the analysis of the WRF-SFIRE plume dynamics, data from the MT, which captured more of the vertical plume structure, are used.

The time series plots of the wind speed measured by the sonic anemometer (dashed line) and simulated by WRFSFIRE (symbols) at the MT at $2 \mathrm{~m}, 10 \mathrm{~m}, 23 \mathrm{~m}$ and $43 \mathrm{~m}$ a.g.l. are shown in Fig. 8. The solid lines are the 5-point moving means of wind speed measurements. The FireFlux time series in Fig. 8 show disturbed wind speeds before, during, and after the fire plume passes the MT. Passage is not marked by 


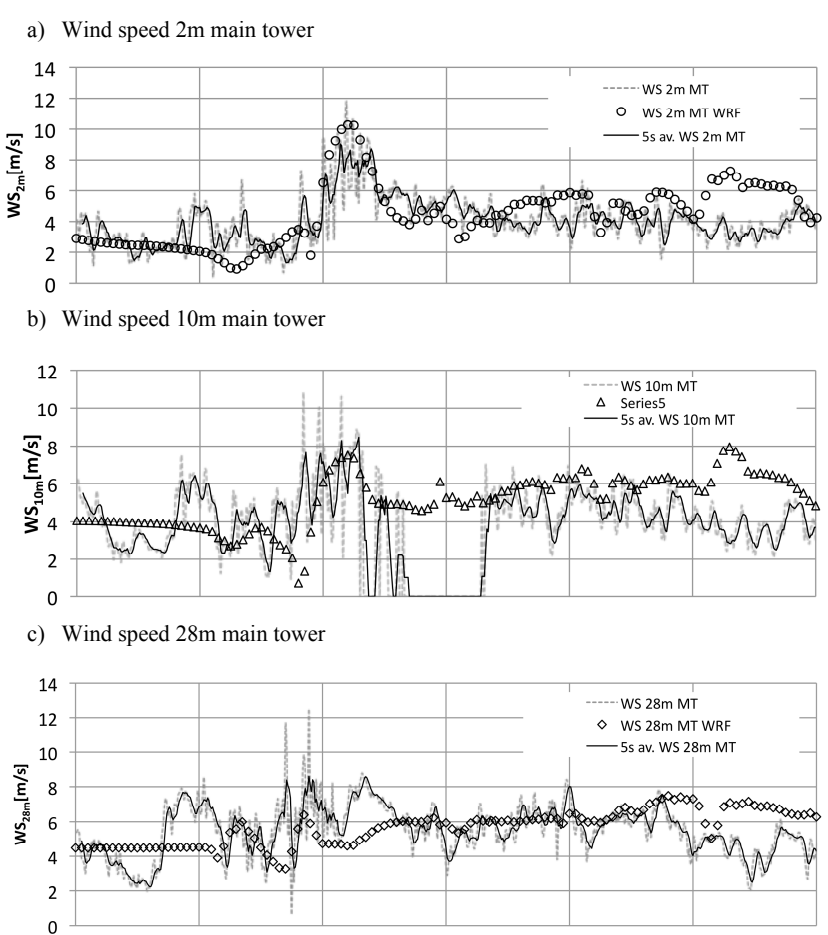

d) Wind speed $43 \mathrm{~m}$ main tower

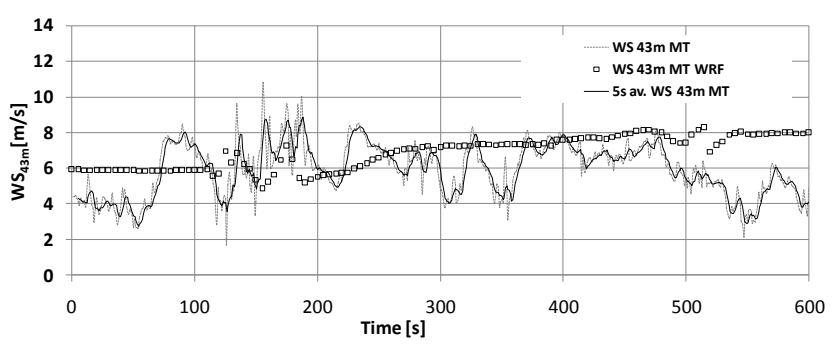

Fig. 8. Time series of horizontal wind speed (WS) at MT levels: (a) $2 \mathrm{~m}$, (b) $10 \mathrm{~m}$, (c) $28 \mathrm{~m}$, and (d) $43 \mathrm{~m}$. Gray dashed lines show $1 \mathrm{~Hz}$ measurements, black solid lines $5 \mathrm{~s}$-averaged values, symbols (circle, triangle, diamond, square) model data at the four MT measurement levels.

a distinct rise and fall in wind speed as it was with temperature, and this is especially true at upper-tower levels $28 \mathrm{~m}$ (Fig. 8c) and $43 \mathrm{~m}$ (Fig. 8d). At $2 \mathrm{~m}$ a.g.l. (Fig. 8a) just before fire passage, the wind speeds rise, reaching 6 to $12 \mathrm{~m} \mathrm{~s}^{-1}$ during fire passage, and then fall to values slightly greater than ambient just after fire passage. Wind speeds at $10 \mathrm{~m}$ a.g.l. (Fig. 8b) show similar behavior except that peak values are lower, approximately 4 to $8 \mathrm{~m} \mathrm{~s}^{-1}$. Both measured and 5point moving means in Fig. $8 \mathrm{c}$ and $\mathrm{d}$ show strong fluctuations in wind speed as the FireFlux plume passes the MT. At these levels the FireFlux measurements vary in magnitude and do not display a single peak value.

There is agreement in Fig. 8 between the WRF-SFIRE results and the FireFlux 5-point moving means. Figure 8a and $\mathrm{b}$ show how, during fire passage, although wind speeds fluctuate throughout, the overall trend is well captured by WRF-SFIRE. Simulated and observed wind speeds rise, peak, and then fall. At $10 \mathrm{~m}$ a.g.l. the maximum simulated wind speed matches almost exactly the filtered observations (with a $0.2 \mathrm{~m} \mathrm{~s}^{-1}$ negative bias), while at $2 \mathrm{~m}$ a.g.l. the model overestimates the peak wind speed by only $1.2 \mathrm{~m} \mathrm{~s}^{-1}$. Neither time series of observed or model wind speeds at the higher elevations display a strong response to the fire plume's passage. At these levels fluctuations in ambient wind speed are similar in amplitude to those associated with fire plume passage, making the quantification of the fire's effect on the wind speed practically impossible. It can be said that before plume passage WRF-SFIRE wind speeds at $28 \mathrm{~m}$ and $43 \mathrm{~m}$ are in overall mean agreement with FireFlux observations. After plume passage, WRF-SFIRE wind speeds at $28 \mathrm{~m}$ and $43 \mathrm{~m}$ are overall greater than FireFlux observations. As discussed before, considerable variation of plume properties in the upper levels of a highly turbulent convective plume is not unrealistic, which makes even this level of agreement between predicted results and measurements acceptable.

The WRF-SFIRE wind speeds shown in Fig. 8 behave as described by Clements et al. (2007). As the fire front approaches the MT, the surface wind speed more than triples, and before the horizontal wind increase there is a brief period of calm that, as suggested by Clements et al. (2007), is associated with horizontal convergence in the flow ahead of the fire line that coincided with increased vertical motion. Clements et al. (2007) have the wind direction shifting from northeasterly to southerly at 12:45:50 CST, approximately $50 \mathrm{~s}$ before the head fire reached the MT. As the fire front passed the MT at 12:46:40 CST, wind direction switched back to ambient northerly flow, while wind speeds increased from approximately $3 \mathrm{~m} \mathrm{~s}^{-1}$ to over $10 \mathrm{~m} \mathrm{~s}^{-1}$. At the upper levels of the MT, there were large increases in wind speed, but not as long in duration as observed at the surface. While the vertical profile of the ambient wind shows wind speed increasing almost logarithmically with height, both observations and the simulation indicate that, during passage of the fire front, the maximum wind speed occurs at the surface and decreases in magnitude with height.

\subsubsection{Fire-induced updraft}

Figure 9 is the same as Fig. 8 except for vertical wind speed. The first fire-induced updraft occurs roughly $200 \mathrm{~s}$ into the simulation as the fire line approaches the MT, and Fig. 8a shows that this occurs around $25 \mathrm{~s}$ before the peak in temperature. The updraft passes the tower, and it is then followed by a strong downdraft. The model's ability to resolve the updraft velocity at $2 \mathrm{~m}$ a.g.l. is limited. The $2 \mathrm{~m}$ height corresponds roughly to the model's first level above the ground. Since vertical velocity is set to zero at the first model level (ground), the model underestimates vertical wind variations close to the surface. Nonetheless, as shown in Fig. 9a, at 2 m a.g.l., the updraft followed by a decrease in the vertical velocity 
a) Vertical velocity $2 \mathrm{~m}$ main tower

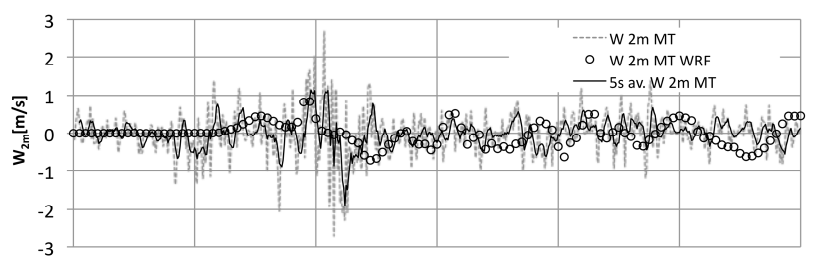

b) Vertical velocity $10 \mathrm{~m}$ main tower

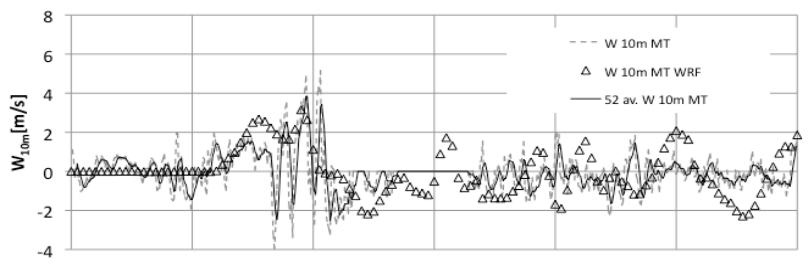

c) Vertical velocity $28 \mathrm{~m}$ main tower

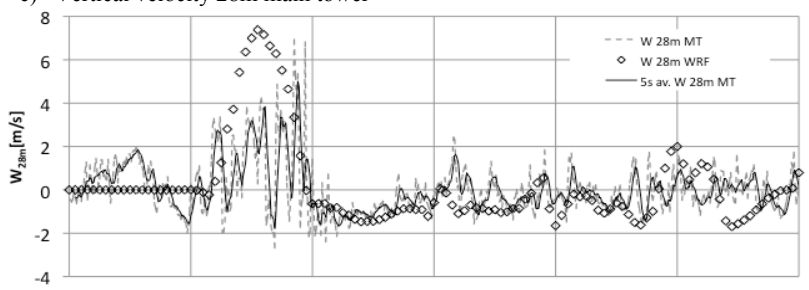

d) Vertical velocity $42 \mathrm{~m}$ main tower

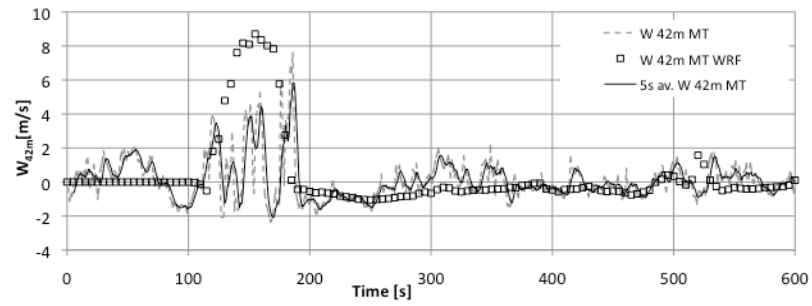

Fig. 9. As in Fig. 8 except for vertical wind speed.

and downdraft of similar strength are still captured realistically by the model.

The model and FireFlux observations displayed in Fig. 9 show that the maximum updraft velocity associated with plume passage increases with height, while the downdraft stays at a similar strength at all heights. Figure $9 \mathrm{c}$ and d indicate that the model overestimated upward velocity at higher levels. The underestimation in the simulated horizontal wind speed at these levels shown by Fig. 8c and d could indicate that the modeled plume was not tilted downstream enough (was too vertical), so that the vertical wind component was overestimated while the horizontal one was underestimated. However, a more vertical plume would result in delayed plume arrival at higher elevations. Figure $9 \mathrm{c}$ and $\mathrm{d}$ indicate that this is not the case; the timing of the model updraft velocity peaks is captured correctly at $28 \mathrm{~m}$ and $43 \mathrm{~m}$ a.g.l. It is more likely that the discrepancy between measured and simulated vertical velocities at upper levels results from the model overestimating the fire front depth, consequently affecting the amount of total heat released into the atmosphere, and therefore the plume updraft speeds. At low elevations, for reasons just discussed, simulated updraft velocities are numerically limited, so they match well with observations. At higher elevations, the model responds more freely to the excessive heating by increasing the vertical velocity within the plume.

\subsubsection{Spatial structure of the fire-induced flow}

Based on the good agreement between FireFlux observations and WRF-SFIRE results seen in Figs. 4 to 9, a more detailed analysis of the possible dynamics responsible for FireFlux behavior as the fire passed the MT and ST may be attempted using the WRF-SFIRE simulation. Here model flow properties $w$, the vertical $z$ velocity component, and $\left|\mathbf{V}_{\mathrm{h}}\right|$, the magnitude of the horizontal wind velocity, are examined, along with the following wind features:

$\delta=\frac{\partial u}{\partial x}+\frac{\partial v}{\partial y}$,

the divergence in the horizontal $x-y$ flow, and

$\zeta^{x}=\frac{\partial w}{\partial y}-\frac{\partial v}{\partial z}$,

the $x$ component of vorticity due to the development of shear in the $y-z$ flow. Here $u, v$, and $w$ are the $x, y$, and $z$ components of the flow. The separation or coming together of flow parcels in the $x-y$ plane is described by $\delta$, where $\delta>0$ signifies divergence and $\delta<0$ signifies convergence of flow parcels. The spin or rotation of flow parcels in the $y-z$ plane is described by $\zeta^{x}$, where $\zeta^{x}>0$ signifies cyclonic or counterclockwise rotation and $\zeta^{x}<0$ signifies anticyclonic or clockwise rotation of flow parcels. Figures 10 and 14 are $x-y$ cross sections that illustrate WRF-SFIRE behavior at $3 \mathrm{~m}$ a.g.l. (the second height level in the model simulation) at two times: 3:45 [min:s] when the fire front reached the MT; and 7:45 [min:s] when the fire line reached the ST. Figures 11 and 15 are $y-z$ cross sections that illustrate the WRF-SFIRE behavior at $x=465 \mathrm{~m}$ (location of the towers) at these two times.

Figure 10 shows all of the flow features described by Clements et al. (2007) for 3:40 [min:s]. As the fire front approached the MT, the surface wind speed more than tripled, and before the horizontal wind increase, there was a brief period of calm associated with horizontal convergence ahead of the fire line that coincided with increased vertical motion. Wind vectors in Fig. 10 show clearly how, just ahead of the MT and the fire head, the direction and speed of the horizontal wind changed from ambient wind conditions of mainly northerly flow of approximately $3 \mathrm{~m} \mathrm{~s}^{-1}$ to the almost reverse direction and almost calm wind conditions. The model wind behavior is very similar to the wind behavior seen in the Linn and Cunningham (2005) FIRETEC simulation of a $100 \mathrm{~m}$ long grass fire line in low $\left(1 \mathrm{~m} \mathrm{~s}^{-1}\right)$ ambient wind conditions (their Fig. 2). Figure 10b, c and d show, respectively, considerable horizontal divergence, large horizontal wind speeds (10 to $12 \mathrm{~m} \mathrm{~s}^{-1}$ ), and significant downdrafts just 


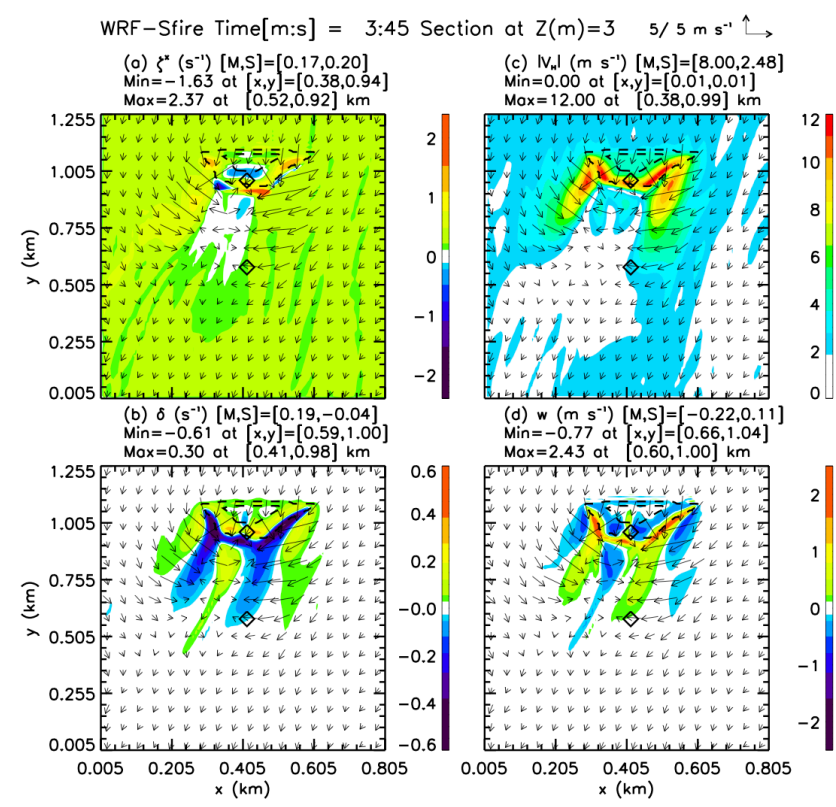

Fig. 10. Horizontal cross sections for $3 \mathrm{~m}$ a.g.l. of (a) horizontal $x$ vorticity $\zeta^{x}\left(\mathrm{~s}^{-1}\right)$, (b) horizontal divergence $\delta\left(\mathrm{s}^{-1}\right)$, (c) speed of horizontal wind $\left|\mathbf{V}_{\mathrm{H}}\right|\left(\mathrm{m} \mathrm{s}^{-1}\right)$, and (d) vertical velocity $w\left(\mathrm{~m} \mathrm{~s}^{-1}\right)$ at 3:45 [min:s] into the WRF-SFIRE simulation. Magnitudes of each contour are indicated by colors in bar plots on the right. For each field, minimum and maximum values, plus their $(x, y)$ positions on cross section are given. Vectors denote wind components in $x-y$ plane where magnitude is scaled as indicated in the top right corner of plot. Black dotted contour lines delineate the surface fire perimeter. Note that the (aspect) ratio between the height of each plot to its width is not equal to one. Plots show features lengthened in the $y$ direction compared to the $x$ direction. The $(x, y)$ locations of the MT and ST are indicated by black diamonds.

behind and along entire leading edge of the fire front. Horizontal convergence and vertical velocity are most significant immediately out ahead of the fire front. Convergence in the horizontal wind is strongest at the base of the narrow updraft. At the time of FFP, in agreement with observations, the WRF-SFIRE horizontal wind speeds increased due to the fire-induced updraft and surface convergence, while background winds outside the burn perimeter remained constant.

Figure 10 displays additional structure to the flow. Figure 10a indicates positive $x$-vorticity $\left(\zeta^{x}\right)$ at the MT location and the leading edge of the fire front, and negative behind. Downstream flow features are associated with horizontally oriented convective rolls. Out ahead of the fire head are divergence, weak horizontal wind, and downward motion, between strong convergence, significant horizontal wind speeds, and upward motion. The convergence out ahead of the fire front on either side of the fire head may be responsible, in part, for the observation of Clements et al. (2007) that the convergence zone was farther ahead of the fire front than previously thought. The model shows the fire head moving towards the south-southwest as it reaches the MT.

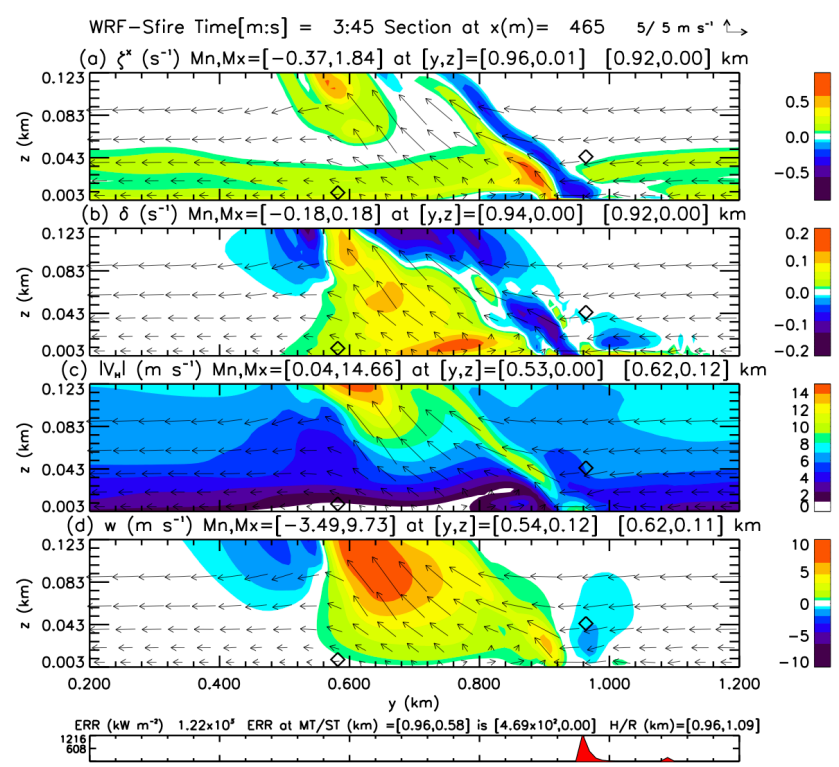

Fig. 11. As in Fig. 10 except for vertical $y-z$ cross sections at $x=465 \mathrm{~m}$. The bottom plot displays the energy release rate (ERR) $\left(\mathrm{kW} \mathrm{m}^{-2}\right)$ from the surface fire as a function of $y$. Maximum rear and head $(\mathrm{R} / \mathrm{H})$ distances $(\mathrm{km})$ advanced by the fire are given, along with fire flux (ERR) values at the surface locations of the MT and ST. The top locations of the MT and ST are indicated by black diamonds.

Figure 11 shows $y-z$ cross sections through the MT and fire head at time 3:40 [min:s]. By comparing Fig. 10a and d to Fig. 11a and d, it is seen that the significant counterclockwise (clockwise) $\zeta^{x}$ ahead of (behind) the leading edge of the fire head coincides with $\frac{\partial w}{\partial y}<0\left(\frac{\partial w}{\partial y}>0\right)$ as part of the model plume's updraft (relatively weaker trailing downdraft).

As in Fig. 10, Fig. 11 shows, near the surface, divergence, weak to calm horizontal wind speeds, and weak vertical motion out ahead of the fire head. The position and distribution of energy release rate (ERR) in the fire's head and rear line are seen in the bottom plot in Fig. 11. The maximum ERR is $861 \mathrm{~kW} \mathrm{~m}^{-2}$ at the fire's front. The wind vectors show winds shifting to undisturbed steady northerly flow once the fire front has passed. Observations and model results indicate that just as the fire front passed the MT a period of downward motion occurred. It is not clear that the downdraft rear of the fire front seen in Figs. 10d and 11d is the cause of fire-induced winds as suggested by Sun et al. (2006) and discussed by Clements et al. (2007); it may be subsidence developing in response to the fire plume's sudden and strong convective updraft. Both observations (Clements et al., 2007) and model results (Fig. 11) report the largest wind speeds occurred in uppermost plume level that was measured by the MT. In Fig. 11 the strongest vertical motion, horizontal wind speeds, and convergence occur at approximately $0.11 \mathrm{~km}$ a.g.l. 


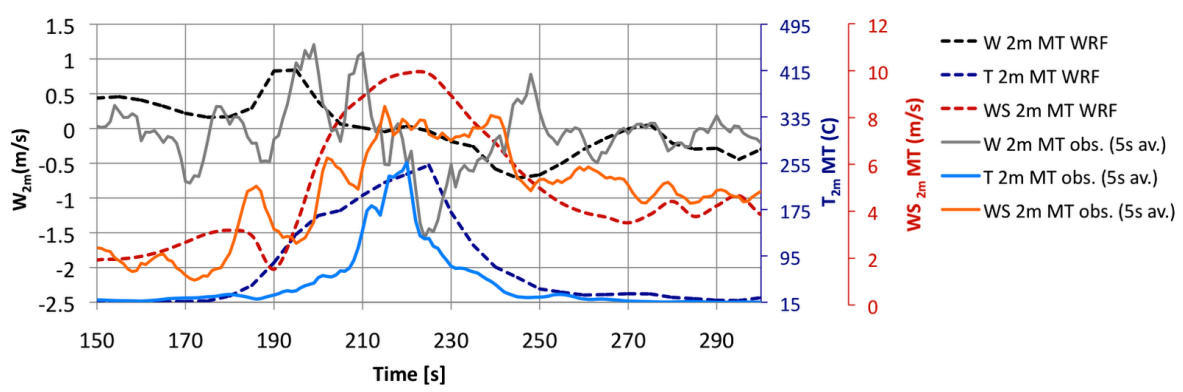

Fig. 12. Time series from the MT of the simulated (dashed lines) and observed (solid lines) updraft velocity $(W)$, temperature $(T)$ and horizontal wind speed (WS) at $2 \mathrm{~m}$. Observational results are presented as $5 \mathrm{~s}$ averages of the original $1 \mathrm{~Hz}$ data.

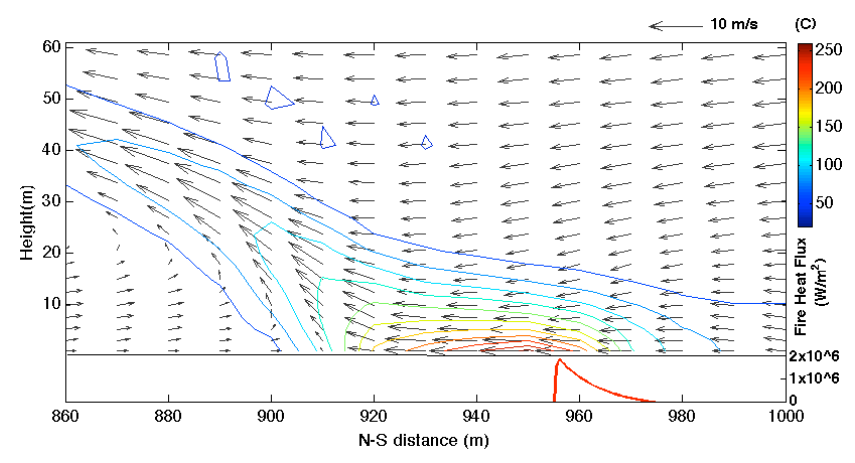

Fig. 13. Vertical $y-z$ cross section at $x=465 \mathrm{~m}, 225 \mathrm{~s}$ into simulation. Vectors denote wind components in $y-z$ plane where magnitude is scaled as indicated in the top right corner of plot. Contour lines represent air temperature $\left({ }^{\circ} \mathrm{C}\right)$, and the magnitude of each contour line is indicated by the color bar on the right side of the plot. The red thick line shows the ERR $\left(\mathrm{W} \mathrm{m}^{-2}\right)$ computed on the fire grid.

Clements et al. (2007) and Fig. 11a suggest a horizontal vortex immediately in front of the fire front at the MT. Clements et al. (2007) also describe soot particles (seen in video and time-lapse photography) dropping out in front of the head fire during the fire passage at the MT. Figure 11a indicates two regions of counterclockwise rotation: a weaker one at upper levels near $0.12 \mathrm{~km}$ a.g.l., and a stronger one at the surface just downstream of the fire front at $y=0.96 \mathrm{~km}$. It may be that the soot particles observed by Clements et al. (2007) were entrained into the plume by the stronger surface horizontal vortex, carried up into the plume by this circulation, and then dropped out downstream of the fire.

Close-ups of model results and observations of temperature and $w$ values during FFP at the MT are displayed in Figs. 12 and 13. Peaks in the observed and simulated vertical velocity (Fig. 12; gray solid and dashed black lines, respectively) arrive earlier at the MT than peaks in observed and simulated temperature (Fig. 12; solid and dashed blue lines, respectively). Figure 13 shows that the WRF-SFIRE updraft core is situated ahead of the fire front, whose position is identified by the maximum in the ERR. The strongest surface convergence is associated with calm surface wind speed and located at the base of the plume's updraft, and both model results and observations suggest that these features are located ahead of, not in or above, the fire's head. Because of the downstream shift, ahead of the fire front, by convergence in the horizontal flow and associated upward motion, fire spread is driven by a local fire-induced wind (Fig. 12; dashed red and solid orange lines) of much greater magnitude than the ambient one. Figure 12 shows that peaks in the simulated wind speed (dashed red line) and temperature (dashed blue line) are collocated. Strong surface winds cross the fire line, advecting fire-heated air downwind, where the warmed, buoyant air converges to form the base of the fire's plume. Note that the maximum ERR of $\sim 2 \mathrm{MW} \mathrm{m}^{-2}$ at the MT seen in Fig. 13 is the WRF-SFIRE instantaneous fire-grid mesh-averaged value. Using $2 \mathrm{~m}$ a.g.l. thermocouple and vertical wind measurements, Clements et al. (2007) estimated $1 \mathrm{MW} \mathrm{m}^{-2}$ as a heat flux maximum. Note that the previous atmospheric grid-averaged ERR of $\sim 1.216 \mathrm{MW} \mathrm{m}^{-2}$ compared to the $2 \mathrm{~m}$ fire-mesh ERR of $2 \mathrm{MW} \mathrm{m}^{-2}$ indicates the sensitivity of the magnitude of model properties to gridvolume averaging.

Figure 14 indicates that the WRF-SFIRE fire head continues to move towards the southwest, and the model fire reaches the ST at 7:45 [min:s]. Figure 14b, c and d show, respectively, considerable horizontal divergence, large horizontal wind speeds (up to $19 \mathrm{~m} \mathrm{~s}^{-1}$ ) and updrafts along and ahead of the leading edge of the model fire front. Convergence in the horizontal wind is strongest at the base of two updrafts positioned immediately out ahead of the fire front. The simulation shows the increased depth of the fire front and the fire, along with the winds in the southeastern portion of the fire domain veering to the southwest. As the model fire front approaches the ST, the fire-induced flow develops flow features not seen at the MT at 3:45 [min:s] (Fig. 10). Wind vectors show clearly how, out ahead of the ST and the fire front, the horizontal wind is extremely turbulent and changed considerably from ambient wind conditions. This model wind behavior is very similar to the wind behavior seen in the Linn and Cunningham (2005) FIRETEC simulation of a $100 \mathrm{~m}$ long grass fire line in similar ambient 


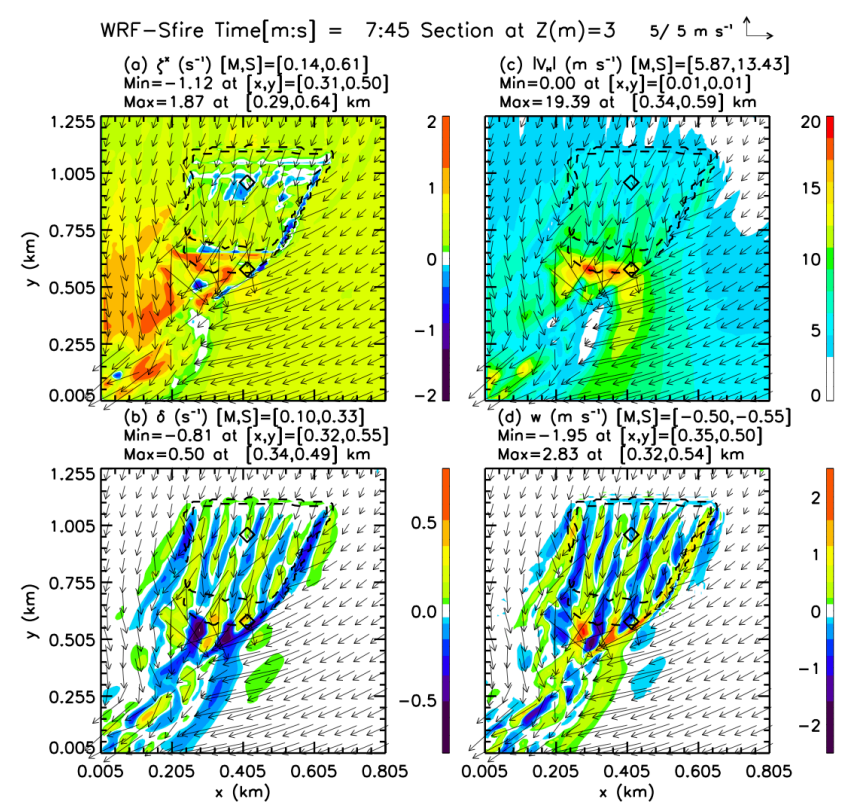

Fig. 14. As in Fig. 10 except for 7:45 [min:s] into the WRF-SFIRE simulation.

$\left(3 \mathrm{~m} \mathrm{~s}^{-1}\right)$ wind conditions (their Fig. 3). Figure 14 shows complex patterns to $\zeta^{x}, \delta$, and $w$, not just out ahead of the fire, but over the entire area enclosed by the fire perimeter. There are alternating strips or streaks of up/down vertical motion coincident with convergence/divergence in the horizontal flow field. These appear to be organized horizontal rolls or eddies embedded in the burning area and aligned with the mainly northerly background flow, similar to the convective instabilities known as "cloud streets" that are common in the atmosphere (Brown, 1980; Etling and Brown, 1993). It should be noted that these fire "streets" did not develop until the Rothermel default no-wind fire ROS was increased from $0.02 \mathrm{~m} \mathrm{~s}^{-1}$ to $0.1 \mathrm{~m} \mathrm{~s}^{-1}$. There are no FireFlux data to validate this result, but this flow pattern is similar to the convective and radiative heating patterns seen in the Cunningham and Linn (2007) FIRETEC simulations of $100 \mathrm{~m}$ long grass fire lines (their Fig. 4). These model results suggest that the heat released by actively moving fire flanks and back is essential to the production of these dynamic "fingers."

Figure 15 shows $y-z$ cross sections through the ST and fire head at time 7:45 [min:s]. As before, significant counterclockwise (clockwise) $\zeta^{x}$ ahead of (behind) the leading edge of the fire head coincides with $\frac{\partial w}{\partial y}<0 \quad\left(\frac{\partial w}{\partial y}>0\right)$ as part of the model plume's updraft (relatively weaker trailing downdraft). The wind vectors do not show winds shifting to undisturbed steady northerly flow once the fire front has passed. Between the front and backfire lines, at 0.58 and $1.12 \mathrm{~km}$ in the $y$ direction, respectively, flow is disturbed in the region of the fire showing what is likely the result of the convective instabilities or "fingering" seen in Fig. 14. The

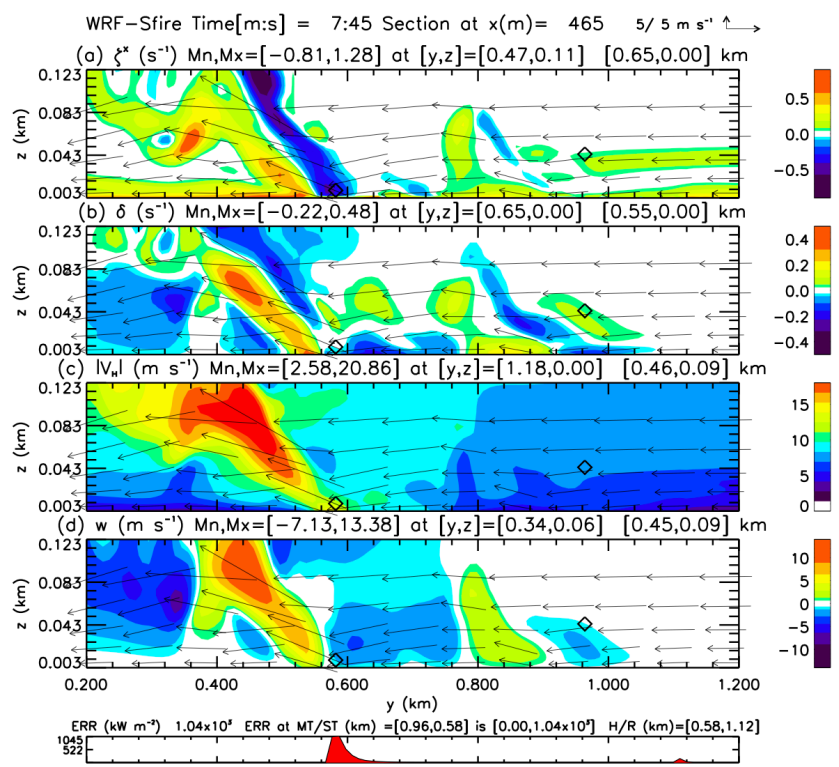

Fig. 15. As in Fig. 11 except for 7:45 [min:s] into the WRF-SFIRE simulation.

model results indicate that, just as the fire front passed the ST, a period of downward motion occurred. The position and distribution of heating rates in the fire's head and rear line are seen in the bottom plot in the figure. Averaged on the WRF atmospheric grid mesh, the maximum ERR (energy release rate) was $1045 \mathrm{~kW} \mathrm{~m}^{-2}$ at the fire's front (bottom plot in Fig. 15).

As before at 3:45 [min:s], wind speeds are largest at upper levels in the plume. Figure 15 shows the strongest vertical motion and horizontal wind at approximately $0.45 \mathrm{~km}$ and $0.46 \mathrm{~km}$ a.g.l. Although there are no FireFlux data to validate these ST model results, they are consistent with the plume and fire behavior seen in Fig. 11 for the MT. Model results (not shown) indicate that maximum vertical wind speeds are always found below $400 \mathrm{~m}$ a.g.l., while the largest vertical extent of the plume is approximately $800 \mathrm{~m}$ a.g.l.

\section{Discussion}

The results in Sect. 5 indicate that overall the agreement between WRF-SFIRE and FireFlux was relatively good. It appears the WRF-SFIRE simulated well the evolution of primary flow features in the FireFlux plume. In Sect. 4, it is seen that a few adjustments to WRF-SFIRE were necessary to match FireFlux behavior, especially in the early phase of the fire. Here the importance of these adjustments to WRFSFIRE as a predictor of wildfire behavior is discussed, followed by suggestions for the design of future field campaigns that are required to develop and validate numerical coupled atmosphere-fire prediction models such as WRF-SFIRE. 
It is understood that, after initial ignition, wildfires experience an "acceleration" or growth phase, before reaching an "equilibrium" or quasi-steady rate of spread (Cheney and Gould, 1997). WRF-SFIRE was coded therefore to take this fire growth phase into account, using arrival time at the MT as a guide. By taking the fire's initial growth phase into account, the simulated fire propagation times to the MT compared very well to the observations.

Current operational fire-spread models are formulated for head-fire propagation where, typically, a single generalized default no-wind spread rate is applied along both the fire's back and flanks. But as Mell et al. (2007) demonstrate, there is no general flank- or back-fire-spread rate; modeling the evolution of the entire fire line is a greater challenge, due to the different spread mechanisms, than modeling the behavior of just the head fire. Rothermel's default no-wind rate spread value for the grass of properties shown in Table 2 is $0.02 \mathrm{~m} \mathrm{~s}^{-1}$, which ensures essentially zero spread along the back or flanks of a fire. Used in preliminary WRF-SFIRE runs, this no-wind value did not provide good agreement with the FireFlux fire line's arrival at the ST. The fire front was so skewed that the ST was passed by a fire flank rather than its head. Therefore, in order to achieve realism of the FFP, this value was increased to $0.1 \mathrm{~m} \mathrm{~s}^{-1}$. However, this important parameter impacts the heat release rate, and the result in this study was active flank- and back-fire spread with discernible consequences for fire plume properties and behavior. If flanking fire and backing fire spread are due to different mechanisms, then it is in general not appropriate to apply a single no-wind fire-spread value as done in the Rothermel fire-spread formulation. It was not possible however to determine, using available FireFlux observations, if the simulated flank and back-fire-spread rates reproduced accurately the entire fire perimeter spread or not. It may be worthwhile to investigate the use of fire-spread formulations other than Rothermel's in WRF-SFIRE, such as Balbi et al. (2007), that require a relatively small number of input parameters and provide a variable no-wind fire-spread rate depending on these parameters. Also, as suggested by one of the reviewers, the local no-wind ROS could be derived from a separate model like Prometheus by Canadian Forest Service (Tymstra et al., 2010).

A second fire model parameter that impacts heat release is the fuel depth. Clements et al. (2008) estimated $1.5 \mathrm{~m}$ as the depth of the grass fuel, whereas in this study, in order to produce agreement between simulated and observed fire behavior, a fuel depth of $1.35 \mathrm{~m}$ was used. The Rothermel fire-spread model is particularly sensitive to fuel properties such as moisture content (Jolly, 2007) and the fuel depth. Again, this result suggests that fire growth models other than Rothermel's should be tested in WRF-SFIRE.

A third important fire model feature is the e-folding extinction depth used to parameterize the absorption of sensible, latent, and radiant heat from the fire's combustion into the surface layers of WRF. In this study the flame length estimate of $5.1 \mathrm{~m}$ by Clements et al. (2007) was used to set the extinction depth to $6 \mathrm{~m}$, with the result being that the WRF-SFIRE vertical profile of temperature taken at the main tower was in good agreement with FireFlux observations, whereas the vertical profile of vertical velocity shows WRF-SFIRE values larger than those observed. This relatively good temperature agreement suggests that efforts to distinguish explicitly between or to model the different modes of fire-atmosphere heat transfer (conductive, convective, radiative) may not, at substantially greater computational cost, provide substantially better plume temperature prediction for a relatively simple grass fire. It is noted, however, that for much more complex crown fires this approach may not be valid.

This study provides the opportunity to suggest the design of future field campaigns used to evaluate or validate numerical wildfire models such as WRF-SFIRE. In addition to the observing procedures to measure winds, temperature, humidity, and surface pressure, described in Clements et al. (2007, 2008) and Clements (2010), the following are suggestions for field campaign protocol based on the results of this study.

The experimental layout needs to be measured carefully for spatial dimensions, any special geographic features, and tower and equipment positioning. This suggestion is based on the finding that the evaluation of the simulated fire was sensitive to the accuracy of these features and their locations in the WRF-SFIRE model domain. Positioning done with GPS ranges in accuracy from $10-30 \mathrm{~cm}$ to (more typical) $1-$ $5 \mathrm{~m}$, depending on the GPS receiver.

The position of the initial fire line should be clearly marked and reported, and the timing of the walking-ignition well determined. In addition, to ensure uncomplicated initial fire line behavior, the initial fire line should be as perpendicular as possible to, ideally, a directionally steady background wind. These suggestions are based on the observation that the evolution of the simulated fire appears to be sensitive to any asymmetry in the timing and positioning of the walkingignition and prevailing winds.

The rate of spread, flame length, and heat release per unit area were estimated in FireFlux (Clements et al., 2007) using the BehavePlus application (Andrews et al., 2008) and the weather observations at the time of the burn. In addition therefore, before a burn, it is recommended that the WRF system and the WRF-SFIRE be run separately in the LES (large eddy simulation) mode to provide, respectively, initial fine-scale atmospheric no-fire and fire data for the area of a field experiment to help with micro-siting and utilization of instrumentation (e.g., number and location of measurement towers, measurement levels, measurement frequency, etc.). Before a burn, ideally, efforts should be made to gather in situ high-frequency fine-scale measurements of momentum fluxes, turbulence, and wind that are needed to verify the nofire wind features predicted by WRF-LES in the ABL. WRFLES wind forecasting and nowcasting abilities would be evaluated with comparisons between ensemble averages of the LES turbulent flow results and these field measurements. 
Note that in this study observations at greater than $1 \mathrm{~Hz}$ sampling rate were not needed or used to evaluate WRF-SFIRE.

A LES is inherently unsteady. There are studies, for example Chow and Street (2009), that suggest that, for a LES simulation to predict successfully both mean flow and turbulence in the ABL, it should be provided with inflow conditions based on a separate, predetermined turbulent flow database. The ensemble averages of the no-fire WRF-LES and field data turbulent flow results would be used for this purpose.

The placement of the observing platforms relative to the initial fire line and wind field is important. The tower arrangement in FireFlux was intended to capture the flow and temperature fields at the fire-atmosphere interface as the fire front traveled with the wind and passed each tower consecutively (Clements et al., 2008). It is recommended that taller (main) instrumented towers be placed farther downwind from smaller (shorter) towers. This layout is different from the one used in FireFlux and is based on the observation that the fire line's behavior and plume are, respectively, relatively simple and small in the early stages, growing more complex and taller with time. Clements et al. (2007) note that an array of towers aligned east-west would have provided a better description of the surface flow and verification by direct observation of the fire-induced flow features associated with the combustion-zone winds.

Although a tethersonde system in tower mode with five sondes was deployed during FireFlux, data during the fire are missing due to the loss of the tethered balloon as a result of strong vertical downdrafts during the initial plume impingement on the balloon. These data provide the above-tower (i.e., upper-level) vertical structure of temperature, humidity, and wind in the fire plume, and are especially valuable for a model validation study. Based on WRF-SFIRE results, the maximum plume height was estimated at $800 \mathrm{~m}$ a.g.l., which is a height that only a tethersonde system can measure. It is known now from the FireFlux experience just how strong the tether for the tethersonde system needs to be.

A radiosonde launched on-site just before the burn, instead of a few hours earlier, would be most useful for documenting the background atmospheric conditions. Even without any large-scale synoptic forcing, both wind and temperature can change in just a few hours as part of the normal diurnal cycle or topography-influenced meteorology. Basic, portable, weather stations located upwind and outside the burn perimeter would also provide background meteorological measurements before, up to, and during the burn.

Multiple digital infrared video and visible SLR cameras can be employed to document smoke and flames. Using a still exploratory method, Clark et al. (1999) show how it is possible to calculate convective-scale velocities and heat fluxes from infrared imagery. Doppler lidar (Banta et al., 1992; Charland and Clements, 2013) can also be used to observe the finer scale kinematics of fire plumes.

The spread of the entire fire perimeter should be measured accurately. In FireFlux, even though orange markers were placed in the fuel at $10 \mathrm{~m}$ intervals from $50 \mathrm{~m}$ north to $300 \mathrm{~m}$ south of the main tower to aid in head-fire-spread rate determination, this information was not adequate to evaluate the size and shape of the entire fire perimeter as the fire evolved. Aerial video (recorded from a helicopter) and time-lapse photography can provide information on perimeter spread, but ideally this information should be supplemented with measurements from a surface-based thermocouple array. In FireFlux, soil temperature thermocouples were buried 3 and $10 \mathrm{~cm}$ below the surface, but these were placed only near the base of the MT (Clements et al., 2008). Thermocouples capable of measuring temperatures up to $1200^{\circ} \mathrm{C}$, and housed in a (plastic) unit, buried just below $(5 \mathrm{~cm}$ or so for grass fires, $10 \mathrm{~cm}$ for higher intensity burns) the surface, can be used to determine fire line arrival times.

The FireFlux burn lasted for approximately $17 \mathrm{~min}$. As described in Cheney and Gould (1997), and references therein, the typical fire growth curve for a fire burning under fairly stable fuel moisture and wind conditions takes approximately $30 \mathrm{~min}$ before reaching a quasi-steady rate of spread. Ideally, measurements from burns lasting at least that long would be very valuable for evaluating numerical fire behavior prediction models such as WRF-SFIRE.

\section{Concluding remarks}

In this study, FireFlux observations (Clements et al., 2007, 2008; Clements, 2010) - the first comprehensive set of in situ measurements of turbulence and dynamics in an experimental wildland grassfire - were used to evaluate and improve the forecast capabilities of WRF-SFIRE. The various changes made to WRF-SFIRE have been described. Missing observations in FireFlux made many direct model/observation comparisons difficult. A more complete evaluation of the WRFSFIRE's predictions of surface pressure, evolving wind fields, plume properties, and surface fire perimeter spread is required. Based on the comparisons that were possible, the overall agreement between the simulation and tower measurements in terms of head-fire-spread rates, vertical profiles of temperature, and vertical and horizontal wind speeds is encouraging. A more intensive observational field campaign should be conducted. Based on the FireFlux experience and the results of this study, suggestions are made for optimal experimental pre-planning, design, and execution of such a campaign.

A long-term goal is to develop and test WRF-SFIRE for operational real-time wildfire prediction. Meanwhile, the level of agreement between WRF-SFIRE simulation results and FireFlux observations suggests that it would be feasible to test and use WRF-SFIRE for wildfire management in prescribed burns, smoke dispersion, or emergency evacuation, under wind and terrain conditions similar to FireFlux. 
Acknowledgements. This research was supported in part by Department of Commerce, National Institute of Standards and Technology (NIST), Fire Research Grants Program, grant 60NANB7D6144, NSF grants ATM-0835579 and DMS-1216481. This work partially utilized the Janus supercomputer, supported by the NSF grant CNS-0821794, the University of Colorado Boulder, University of Colorado Denver, and NCAR. The Houston Coastal Center of the University of Houston is acknowledged for financial support for the FireFlux experiment. A gratis grant of computer time from the Center for High Performance Computing, University of Utah, is gratefully acknowledged.

Edited by: M. Kawamiya

\section{References}

Anderson, H.: Aids to determining fuel models for estimating fire behavior, USDA Forest Service, Intermountain Forest and Range Experiment Station, General Technical Report INT-122, 22 pp., 1982.

Andrews, P. L., Bevins, C. D., and Seli, R. C.: BehavePlus fire modeling system, version 4.0: User's guide revised. General Tech. Report RMRS-GTR-106WWW Revised, US Department of Agriculture, Forest Service, Rocky Mountain Research Station, Ogden, UT, 132 pp., 2008.

Balbi, J.-H., Rossi, J.-L., Marcelli, T., and Santoni, P.A. : A 3D Physical Real-Time Model of Surface Fires Across Fuel Beds, Combusion Sci. Tech., 179, 2511-2537, doi:10.1080/00102200701484449, 2007.

Banta, R., Olivier, L., Holloway, E., Kropfli, R., Bartram, B., Cupp, R., and Post, M.: Smoke-column observations from two forest fires using Doppler lidar and Doppler radar, J. Appl. Meteor., 31, 1328-1349, doi:10.1175/15200450(1992)031<1328:SCOFTF>2.0.CO;2, 1992.

Beer T.: The interaction of wind and fire, Bound.-Lay. Meteorol., 54, 287-308, doi:10.1007/BF00183958, 1991.

Beezley, J. D., Kochanski, A., Kondratenko, V. Y., Mandel, J., and Sousedik, B.: Simulation of the Meadow Creek fire using WRFFire, Poster at AGU Fall Meeting 2010, available at: http: //www.openwfm.org/wiki/File:Agu10jb.pdf (last access: 4 July 2011), 2010.

Beezley, J. D.: Importing High-resolution Datasets into Geogrid, Paper P2, 12th WRF Users' Workshop, National Center for Atmospheric Research, 20-24 June 2011, available at: http:// www.mmm.ucar.edu/wrf/users/workshops/WS2011/Extended\% 20Abstracts\%202011/P2_Beezley_ExtendedAbstract_11.pdf (last access: 23 July 2013), 2011.

Brown, R. A.: Longitudinal instabilities and secondary flows in the planetary boundary layer: A review, Rev. Geophys. Space Phys., 18, 683-697, 1980.

Charland, A. M. and Clements, C. B.: Kinematic structure of a wildland fire plume observed by Doppler lidar, J. Geophys. Res. Atmos., 118, 3200-3212, doi:10.1002/jgrd.50308, 2013.

Cheney, N. P. and Gould, J. S.: Fire growth in grassland fuels, Int. J. Wildland Fire, 5, 237-347, doi:10.1071/WF9950237, 1995.

Cheney, N. P. and Gould, J.: Fire Growth and Acceleration, Int. J. Wildland Fire, 7, 1-5, 1997.

Cheney, N. P., Gould, J. S., and Catchpole, W. R.: The influence of fuel, weather and fire shape variables on fire-spread in grass- lands, Int. J. Wildland Fire, 3, 31-44, doi:10.1071/WF9930031, 1993.

Chow, F. and Street, R.: Evaluation of Turbulence Closure Models for Large-Eddy Simulation over Complex Terrain: Flow over Askervein Hill, J. Appl. Meteorol. Climatol., 48, 1050-1065, doi:10.1175/2008JAMC1862.1, 2009.

Clark, T. L., Jenkins, M. A., Coen, J., and Packham, D.: A coupled atmospheric-fire model: Convective feedback on fire line dynamics, J. Appl. Meteorol., 35, 875-901, doi:10.1175/15200450(1996)035<0875:ACAMCF>2.0.CO;2, 1996a.

Clark, T. L., Jenkins, M. A., Coen, J., and Packham, D.: A coupled atmosphere-fire model: role of the convective Froude number and dynamic fingering at the fire line, Int. J. Wildland Fire, 6, 177190, doi:10.1071/WF9960177, 1996 b.

Clark, T. L., Radke, L., Coen, J., and Middleton, D.: Analysis of small-scale convective dynamics in a crown fire using infrared video camera imagery, J. Appl. Meteorol., 38, 1401-1420, doi:10.1175/1520-0450(1999)038<1401:AOSSCD > 2.0.CO;2, 1999.

Clark, T. L., Griffiths, M., Reeder, M. J., and Latham, D.: Numerical simulations of grassland fires in the Northern Territory, Australia: A new subgrid-scale fire parameterization, J. Geophys. Res., 108, 4589, doi:10.1029/2002JD003340, 2003.

Clements, C. B.: Thermodynamic structure of a grass fire plume, Int. J. Wildland Fire, 19, 895-902, doi:10.1071/WF09009, 2010.

Clements, C. B., Zhong, S., Goodrick, S., Li, J., Bian, X., Potter, B. E., Heilman, W. E., Charney, J. J., Perna, R., Jang, M., Lee, D., Patel, M., Street, S., and Aumann, G.: Observing the dynamics of wildland grass fires: FireFlux - a field validation experiment, B. Am. Meteorol. Soc., 88, 1369-1382, doi:10.1175/BAMS-889-1369, 2007.

Clements, C. B., Zhong, S., Bian, X., Heilman, W. E., and Byun, D. W.: First observations of turbulence generated by grass fires, J. Geophys. Res., 113, D22102, doi:10.1029/2008JD010014, 2008.

Coen, J. L.: Simulation of the Big Elk Fire using coupled atmosphere-fire modeling, Intl. J. Wildland Fire, 14, 49-59, doi:10.1071/WF04047, 2005.

Coen, J., Cameron, M., Michalakes, J., Patton, E., Riggan, P., and Yedinak, K.: WRF-Fire: Coupled weather-wildland fire modeling with the Weather Research and Forecasting model, J. Appl. Meteor. Climatol., 52, 16-38, doi:10.1175/JAMC-D-12-023.1, 2013.

Cunningham, P. and Linn, R. R.: Numerical simulations of grass fires using a coupled atmosphere-fire model: Dynamics of fire spread, J. Geophys. Res., 112, D05108, doi:10.1029/2006JD007638, 2007.

Cunningham, P., Goodrick, S. L., Hussaini, M. Y., and Linn, R. R.: Coherent vortical structures in numerical simulations of buoyant plumes from wildland fires, Int. J. Wildland Fire, 14, 61-75, doi:10.1071/WF04044, 2005.

Etling, D. and Brown, R. A.: Roll vortices in the planetary boundary layer: a review, Bound.-Lay. Meteorol., 65, 215-248, 1993.

Filippi, J.-B., Bosseur, F., Mari, C., Lac, C., Lemoigne, P., Cuenot, B., Veynante, D., Cariolle, D., and Balbi, J. H.: Coupled atmosphere-wildland fire modelling, J. Adv. Model. Earth Syst., 1, 9 pp., doi:10.3894/JAMES.2009.1.11, 2009.

Filippi, J.-B., Pialat, X., and Clements, C. B.: Assessment of ForeFire/Meso-NH for wildland fire/atmosphere coupled simulation of the FireFlux experiment, Proceedings of the Combustion 
Institute, 65, 2633-2640, doi:10.1016/j.proci.2012.07.022, 2013.

Finney, M. A.: FARSITE: Fire Area Simulator-model development and evaluation, Res. Pap. RMRS-RP-4, Ogden, UT: US Department of Agriculture, Forest Service, Rocky Mountain Research Station, 1-47, 1998.

Jolly, W. M.: Sensitivity of a surface fire spread model and associated fire behaviour fuel models to changes in live fuel moisture, Int. J. Wildland Fire, 16, 503-509, doi:10.1071/WF06077, 2007.

Kochanski, A., Jenkins, M. A., Krueger, S. K., Mandel, J., Beezley, J. D., and Clements, C. B.: Coupled atmosphere-fire simulations of FireFlux: Impacts of model resolution on its performance, Paper 10.2, Ninth Symposium on Fire and Forest Meteorology, Palm Springs, October 2011, available at: http://ams.confex. com/ams/9FIRE/webprogram/Paper192314.html (last access: July 2013), 2011.

Linn, R.: A transport model for prediction of wildfire behavior, OSTI ID: 505313; Legacy ID: DE97007825 LA-13334-T Technical Report, doi:10.2172/505313, 212 pp., 1997.

Linn, R. and Cunningham, P.: Numerical simulations of grass fires using a coupled atmosphere-fire model: Basic fire behavior and dependence on wind speed, J. Geophys. Res., 110, 2156-2202, doi:10.1029/2004JD005597, 2005.

Linn, R., Reisner, J., Colman, J. J., and Winterkamp, J.: Studying wildfire behavior using FIRETEC, Int. J. Wildland Fire, 11 , 233246, doi:10.1071/WF02007, 2002.

Mandel, J., Beezley, J. D., Coen, J. L., and Kim, M.: Data assimilation for wildland fires. Ensemble Kalman filters in coupled atmosphere-surface models, IEEE Control Syst. Magazine, 29, 47-65, 2009.

Mandel, J., Beezley, J. D., and Kochanski, A. K.: Coupled atmosphere-wildland fire modeling with WRF 3.3 and SFIRE 2011, Geosci. Model Dev., 4, 591-610, doi:10.5194/gmd-4-5912011, 2011.
Mell, W., Jenkins, M., Gould, J., and Cheney, P.: A physics-based approach to modelling grassland fires, Int. J. Wildland Fire, 16, 1-22, doi:10.1071/WF06002, 2007.

Morvan, D. and Dupy, J. L.: Modeling of fire spread through a forest fuel bed using a multiphase formulation, Combustion Flame, 127, 1981-1994, doi:10.1016/S0010-2180(01)00302-9, 2001.

OpenWFM: Fire code in WRF release, Open Wildland Fire Modeling e-Community, available at: http://www.openwfm.org/wiki/ Fire_code_in_WRF_release (last access: November 2012), 2012.

Osher, S. and Fedkiw, R.: Level Set Methods and Dynamic Implicit Surfaces, Springer, New York, 2003.

Papadopoulos, G. D. and Pavlidou, F.-N.: A comparative review of wildfire simulators, Syst. J., 5, 233-243, doi:10.1109/JSYST.2011.2125230, 2011.

Rothermel, R. C.: A mathematical model for predicting fire spread in wildland fires, USDA Forest Service Research Paper INT-115, 1972.

Sullivan, A. L.: Wildland surface fire spread modelling, 1990-2007: 1: Physical and quasi-physical models, Int. J. Wildland Fire, 18, 349-368, doi:10.1071/WF06143, 2009.

Sun, R., Jenkins, M. A., Krueger, S., Mell, W., and Charney, J.: An evaluation of fire-plume properties simulated with the Fire Dynamics Simulator (FDS) and the Clark coupled wildfire model, Canadian. J. Forest. Res., 36, 2894-2907, doi:10.1139/x06-138, 2006.

Sun, R., Krueger, S. K., Jenkins, M. A., Zulauf, M. A., and Charney, J. J.: The importance of fire-atmosphere coupling and boundarylayer turbulence to wildfire spread, Int. J. Wildland Fire, 18, 5060, doi:10.1071/WF07072, 2009.

Tymstra, C., Bryce, R., Wotton, B., Taylor, S., and Armitage, O.: Development and Structure of Prometheus: the Canadian Wildland Fire Growth Simulation Model, Northern Forestry Centre, Edmonton, Alberta Canada, 2010. 